\title{
MYOPIC \\ GOVERNMENTS AND \\ WELFARE-ENHANCING \\ DEBT LIMITS
}

by Malte Rieth 


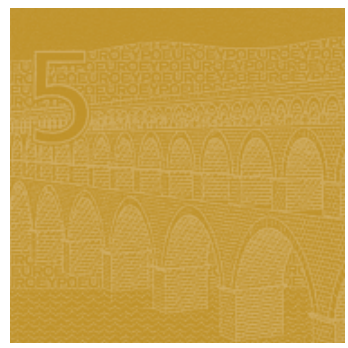

\section{WORKING PAPER SERIES}

NO I308 I MARCH $20 I I$

by Malte Rieth ${ }^{2}$
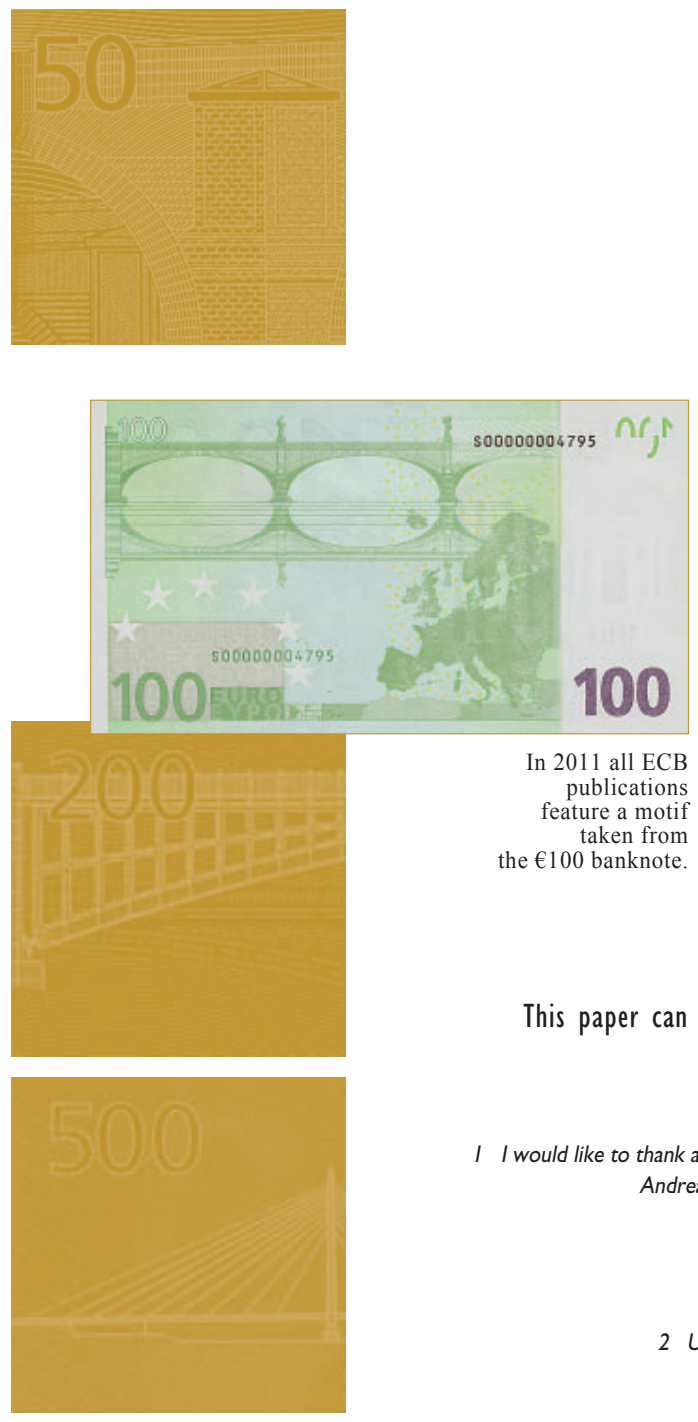

NOTE: This Working Paper should not be reported as representing the views of the European Central Bank (ECB).

The views expressed are those of the authors and do not necessarily reflect those of the $E C B$.

This paper can be downloaded without charge from http://www.ecb.europa.eu or from the Social Science Research Network electronic library at http://ssrn.com/abstract_id = I772570.

I I would like to thank an anonymous referee, Wouter den Haan, Makus Hörmann, Markus Kirchner, Campbell Leith, Ludger Linnemann, Andreas Schabert, and Leopold von Thadden for helpful comments and discussions. I also thank participants of seminars and conferences at the University of Dortmund, Ruhr Graduate School in Economics, European Economic Association Annual Conference 2010 Glasgow, Doctoral Meeting of Montpellier 2010, RGS Doctoral Conference in Economics 2009, and Symposium on Public Economics Granada 2009. 
(C) European Central Bank, 2011

\section{Address}

Kaiserstrasse 29

60311 Frankfurt am Main, Germany

Postal address

Postfach 160319

60066 Frankfurt am Main, Germany

Telephone

+496913440

Internet

http://www.ecb.europa.eu

Fax

+496913446000

All rights reserved.

Any reproduction, publication and reprint in the form of a different publication, whether printed or produced electronically, in whole or in part, is permitted only with the explicit written authorisation of the ECB or the author.

Information on all of the papers published in the ECB Working Paper Series can be found on the ECB's website, http://www. ecb.europa.eu/pub/scientific/wps/date/ html/index.en.html

ISSN 1725-2806 (online) 


\section{CONTENTS}

Abstract

Non technical summary

1 Introduction

2 Model

2.1 Private sector

2.2 Government and resource constraint

2.3 Policy problem

2.4 Equilibrium and steady state analysis

3 Calibration and welfare measure

3.1 Calibration

3.2 Welfare measure

4 Numerical analysis of the soft borrowing constraint

4.1 Long run effects of myopia and the soft borrowing constraint

4.2 Transitional dynamics under a soft borrowing constraint

4.3 Short run dynamics under a soft borrowing constraint

5 Discussion

5.1 Welfare gains under alternative assumptions

5.2 Sensitivity analysis

6 Conclusions

References 


\section{Abstract}

This paper studies welfare consequences of a soft borrowing constraint on sovereign debt which is modeled as a proportional fine per unit of debt exceeding some reference value. Debt is the result of myopic fiscal policy where the government is assumed to have a smaller discount factor than the private sector. Due to the absence of lump-sum taxation, debt reduces welfare. The paper shows that the imposition of a soft borrowing constraint, which resembles features of the Stability and Growth Pact and which is taken into account by the policy maker when setting its instruments, prevents excessive borrowing. The constraint can be implemented such as to (i) control the long run level of debt, (ii) prevent debt accumulation, and (iii) induce debt consolidation. In all three cases the constraint enhances welfare and in a welfare ranking these gains outweigh the short run welfare losses of increasing the costs of using debt to smooth taxes over the business cycle.

Keywords: Myopic governments; debt bias; fiscal constraints; Stability and Growth Pact; social welfare.

JEL classification: $\mathrm{H} 3, \mathrm{H} 63, \mathrm{E} 6$. 


\section{Non-technical summary}

In 2010 the average debt to GDP ratio of the OECD countries reaches 100\%. In the Euro Area this ratio was $70 \%$ already before the outset of the financial crisis. In the absence of lump-sum taxation, high levels of debt reduce social welfare due to the deadweight loss of the taxes needed to service that debt. This paper analyzes how debt and the associated welfare costs can be reduced. It first measures these costs. Then, it proposes a legal restriction on fiscal policy in form of a borrowing constraint and shows how such a restriction leads to an enhancement of social welfare.

According to standard economic theory, a benevolent government will use debt only to smooth taxes in response to budget fluctuations. In the long run debt should be near zero or even negative. However, this prescription contrasts with the observed levels of sovereign debt in most OECD countries. To account for this observation, in the model the government is assumed to be myopic, i.e. it has a lower discount factor than the private sector, giving rise to a 'debt bias'. Myopia can be interpreted as the result of an expected finite planning horizon of the government. Moreover, the government has only access to distortionary taxation in order to finance an exogenously given stream of government consumption. Combined, positive levels of debt and the absence of lump-sum taxation are the source of welfare costs in the model and provide the motivation for an analysis of a debt constraint. More specifically, the paper proposes a constraint on debt but where full compliance by the government is not ensured. The government can violate the constraint but this violation is associated with the payment of a proportional fine to a supranational institution. Rather than a hard $0 / 1$ constraint on sovereign debt, the proposed mechanism hence constitutes a 'soft borrowing constraint' (SBC). The reference value of debt and the tightness of the SBC are treated as if controlled by a supranational institution, resembling features of the Stability and Growth Pact (SGP). The model shows that the proposed SBC can bring down debt to zero in the long run and thereby eliminates the main source of welfare costs, namely positive levels of debt in steady state.

The paper analyses the welfare implications of the SBC in the following four scenarios, providing a welfare ranking according to the relative welfare gains/ losses of the SBC in each of them: First, it considers only long run effects. For the baseline calibration government myopia leads to a level of debt to GDP of about $100 \%$. This is associated with welfare costs of $0.353 \%$ in terms of consumption relative to the zero debt steady state under the fully benevolent planner. The paper shows that by setting the tightness and the reference value of 
debt in the SBC appropriately the supranational institution can bring down debt to zero in the long run, preventing these welfare losses. In the second scenario the paper accounts for the transitional period to the high debt steady state. The paper shows that the imposition of the SBC prevents this transition and the associated welfare costs of $0.141 \%$. Third, the paper considers a debt consolidating transition, induced by the imposition of the SBC, from a high debt steady state without SBC to a new steady state with SBC. The paper shows that for the optimal combination of the tightness of the SBC and the reference value of debt it is possible to induce debt consolidation and realize welfare gains of $0.099 \%$. Finally, the paper looks at the short run dynamics of myopic fiscal policy under a SBC which are compared to the optimal policy of the fully benevolent planner without SBC. Welfare costs of the SBC amount to $0.001 \%$ because the SBC increases the costs of using debt to smooth taxes over the business cycle. The relative welfare costs in the four considered scenarios reflect the conclusion of Lucas (2003) that welfare gains from improved long run policies tend to exceed the potential from further improvements in short run policies. Thus, the paper supports the views of those who like to strengthen the rules of the SGP. It also provides an argument for the inclusion of a debt break into the German constitution or for the advocates of balanced budget rules. 


\section{Introduction}

How can high levels of debt and the associated welfare costs be reduced? In 2010 the average debt to GDP ratio of the OECD countries reaches $100 \% .{ }^{1}$ In the Euro Area this ratio was $70 \%$ already before the outset of the financial crisis. ${ }^{2}$ In the absence of lump-sum taxation, high levels of debt reduce social welfare due to the deadweight loss of the taxes needed to service that debt. ${ }^{3}$ This paper analyzes how debt and the associated welfare costs can be reduced. It first measures these costs. Then, it proposes a legal restriction on fiscal policy and shows how such a restriction leads to an enhancement of social welfare.

According to standard economic theory, a benevolent government will use debt only to smooth taxes in response to budget fluctuations. In the long run debt should be near zero or even negative. ${ }^{4}$ However, this prescription contrasts with the observed levels of sovereign debt in most OECD countries. To account for this observation, in the model the government is assumed to have an objective which differs from that of the representative household.

The set-up of the model is as follows. There are two distortions in the economy. First, following the standard approach of optimal fiscal policy, the government has only access to distortionary taxation in order to finance an exogenously given stream of government consumption. Second, introducing a political distortion, the government is myopic, i.e. it has a lower discount factor than the private sector, giving rise to a 'debt bias'. Myopia can be interpreted as the result of an expected finite planning horizon of the government. These two distortions combined are the source of welfare costs and provide the motivation for an analysis of a debt constraint. More specifically, the paper proposes a constraint on debt but where full compliance by the government is not ensured. The government can violate the constraint but this violation is associated with the payment of a fine. Rather than a hard $0 / 1$ constraint on sovereign debt, the proposed mechanism hence constitutes a "soft borrowing constraint' (SBC). The SBC resembles features of the Stability and Growth Pact (SGP) which is a particular example of such a mechanism. In the limit, i.e. for very high fines associated with a violation of the constraint, the SBC implies a balanced budget rule. The main contribution of the paper is to show that the proposed SBC enhances welfare in an economy where the optimizing government takes into account this SBC as well as the equilibrium reactions of households.

The model builds on Aiyagari, Marcet, Sargent, and Seppälä (2002). The government has

\footnotetext{
${ }^{1}$ See OECD (2009).

${ }^{2}$ See ECB (2009).

${ }^{3}$ See, for example, Elmendorf and Mankiw (1999).

${ }^{4}$ See, for example, Aiyagari, Marcet, Sargent, and Seppälä (2002).
} 
to finance an exogenously given and stochastic stream of government consumption. It has access to flat rate taxes on labour income and issues one-period non-state-contingent bonds. For the sake of realism, markets for government bonds are thus incomplete. I include the following two features into this set up.

First, the government is myopic. Myopia is modeled as a lower discount factor of the government than that of the private sector. Myopia can be interpreted as the result of an expected finite planning horizon which corresponds to the prospective duration of the government's survival in power, following Grossman and Van Huyck (1988). The difference between the discount factors creates a debt bias: The policy maker lowers tax rates in the near future by issuing debt. In the long run, this policy leads to a positive level of debt which in turn requires higher taxes to finance higher debt servicing costs. Persson and Svensson (1989) and Alesina and Tabellini (1990), among others, model the political process which gives rise to the debt bias as a political conflict between different interest groups. ${ }^{5}$ Here, I follow Grossman and Van Huyck (1988) and assume that the government is myopic but otherwise benevolent because it allows staying conceptually close to the standard normative approach of the Ramsey planner which can then be used as a natural benchmark to compute the welfare consequences of the SBC. ${ }^{6}$

Second, following Beetsma, Ribeiro, and Schabert (2008), I introduce a SBC which is modeled as a proportional fine per unit of debt exceeding some reference value. ${ }^{7}$ The SBC includes a threshold on debt which is taken into account by the government when maximizing its objective. However, the constraint can be violated by the government which then has to pay the associated fine. The reference value of debt and the tightness of the SBC are treated as if controlled by a supranational institution and are thus taken as given by the government. I show that the proposed SBC can bring down debt to zero in the long run and thereby eliminates the main source of welfare costs, namely positive levels of debt in steady state.

To provide a ranking of the welfare implications of the SBC, I consider the following four scenarios: First, for illustration purposes and to obtain a quantitative impression of both stochastic and non-stochastic steady state effects, I consider only long run welfare effects of myopia and the SBC. For the baseline calibration government myopia leads to a level of debt to GDP of about $100 \%$. This is associated with welfare costs of $0.353 \%$ in terms of consumption relative to the zero debt steady state under the fully benevolent planner.

\footnotetext{
${ }^{5}$ See Alesina and Perotti (1994) for a review of the political economy of budget deficits.

${ }^{6}$ This assumption is also used by Kumhof and Yakadina (2007).

${ }^{7}$ While this specification resembles features of the SGP, the aim is not to model the precise deficit procedure prescribed by the rules of the SGP.
} 
The paper shows that by setting the tightness and the reference value of debt in the SBC appropriately the supranational institution can bring down debt to zero in the long run, preventing these costs. In the second scenario I account for the transitional period to a high debt steady state which leads to welfare costs of $0.141 \%$. I show that the imposition of the SBC prevents the transition and the associated costs. Third, I consider a debt consolidating transition, induced by the imposition of the SBC, from a high debt steady state without SBC to a new steady state with SBC. I show that for the optimal combination of the tightness of the SBC and the reference value of debt it is possible to induce debt consolidation from $100 \%$ of GDP to $40 \%$ and thereby realize welfare gains of $0.099 \%$. Finally, I look at the short run dynamics of myopic fiscal policy under a SBC which are compared to the optimal policy of the fully benevolent planner without SBC. Welfare costs of the SBC amount to $0.001 \%$ because the SBC increases the costs of using debt to smooth taxes over the business cycle. The relative welfare costs in the four considered scenarios reflect the conclusion of Lucas (2003) that welfare gains from improved long run policies tend to exceed the potential from further improvements in short run policies. ${ }^{8}$

The next section lays out the model and the policy problem. Section 3 presents the calibration and the welfare measure. Section 4 provides the results. Section 5 discusses the results and their sensitivity to alternative assumptions before Section 6 concludes.

\section{The model}

In this section, I first describe the economy and define the competitive equilibrium for a given policy. Then, I set up the policy problem and define the equilibrium under optimizing fiscal policy. Finally, I analyze the equilibrium and its steady state. The sources of uncertainty in the economy are government consumption and productivity. The shocks to these variables materialize at the beginning of each period and are observed by all agents when taking their decisions. Moreover, all agents have rational expectations.

\footnotetext{
${ }^{8}$ The numbers in case four are smaller than in Stockman (2001) who finds larger welfare costs associated with a balanced budget regime. However, he derives his results from an economy with capital and complete markets. Further, the role of balanced budget rules as an additional source of instability, as suggested by Schmitt-Grohé and Uribe (1997), is not considered in my welfare analysis. Moreover, I do not consider benefits of government debt for households as in Aiyagari and McGrattan (1998). Finally, it should be mentioned that, given the level of abstraction of the theoretical model, the welfare results are used to provide a welfare ranking of the consequences of the SBC under alternative scenarios rather than to provide realistic estimates of the welfare effects of the SBC.
} 


\subsection{Private sector}

The private sector consists of households, firms, and a financial intermediary. There is no population growth and no technological progress.

\subsubsection{Households}

Households are identical, infinitely-lived, and of mass one. The objective of a representative household is given by:

$$
E_{0} \sum_{t=0}^{\infty} \beta^{t} u\left(c_{t}, n_{t}\right)
$$

where $c_{t}$ denotes consumption, $n_{t}$ working time, $\beta \epsilon(0,1)$ is the discount factor, and $u(c, n)$ is additively separable. The household's total amount of time is normalized to one and is divided between working time and leisure. It earns the wage rate $w_{t}$ and has to pay a flatrate $\operatorname{tax} \tau_{t}$ on labour income. The household can invest in one-period non-state-contingent government bonds $b_{t+1}$ at the period $t$ price $1 / R_{t}$, where $R_{t}$ is the gross rate of return. For the sake of realism, markets are thus incomplete like in Aiyagari, Marcet, Sargent, and Seppälä (2002). The budget constraint reads:

$$
c_{t}+\frac{b_{t+1}}{R_{t}}+\Phi_{t} \leq\left(1-\tau_{t}\right) w_{t} n_{t}+b_{t}+\pi_{t}
$$

where $\Phi_{t}$ are transaction costs which have to be paid to a financial intermediary when the household enters the capital market, maintaining either a short or a long position. They are assumed to be quadratic in the ratio of bond holdings over per capita output and proportional to GDP, where the latter is taken as given by the household:

$$
\Phi_{t}=\frac{\phi}{2} y_{t}\left(\frac{b_{t+1}}{y_{t}}\right)^{2}
$$

Following Heaton and Lucas (1996), rather than trading costs, the transaction costs can be interpreted as a wedge between the borrowing and lending rates due to monitoring and other costs incurred each period, depending on the stock of debt outstanding. The transaction costs imply that an increase of the level of debt to GDP leads to an increase of the interest rate on government bonds. This implication commands broad empirical support (see Gale and Orszag, 2003, Engen and Hubbard, 2004, or Laubach, 2009). Here, the transaction costs ensure the existence of a well defined steady state in all considered scenarios (see Sections 2.4 and 4). The main advantage of this functional form, which follows Schmitt- 
Grohé and Uribe (2003), Neumeyer and Perri (2005), and Kumhof and Yakadina (2007), is its analytical tractability. ${ }^{9}$ The firms' and financial intermediary's profits $\pi_{t}$ are redistributed to the household in a lump-sum way.

The household maximizes (1) subject to (2) and (3) and a no-Ponzi-game condition which prevents the household to make excessive debts. ${ }^{10}$ The first order conditions can be combined to

$$
\begin{aligned}
\left(1-\tau_{t}\right) w_{t} u_{c, t} & =-u_{n, t} \\
u_{c, t}\left(\frac{1}{R_{t}}+\phi \frac{b_{t+1}}{y_{t}}\right) & =\beta E_{t} u_{c, t+1} .
\end{aligned}
$$

Moreover, the transversality condition holds: $\lim _{t \rightarrow \infty} \beta^{t+1} E_{0}\left[u_{c, t+1} b_{t+1}\right]=0$. Equation (5) shows that an increase of the ratio of debt to GDP tends to increase the interest rate via an increase of transaction costs.

\subsubsection{Firms and financial intermediary}

Competitive firms produce with the linear production function $y_{t}=a_{t} n_{t}$, where $a_{t}$ denotes productivity which follows an exogenously given stochastic process. They pay a wage rate equal to the marginal product of labour: $w_{t}=a_{t}$. The financial intermediary has zero marginal and fixed costs and since firms make zero profits $\Phi_{t}=\pi_{t}$ holds.

\subsection{Government and resource constraint}

The government has to finance an exogenously given and stochastic stream of government consumption $g_{t}$. It has access to flat-rate taxes on labour income and issues one-period non-state-contingent bonds. The government's objective is described in detail in the next subsection.

I introduce a constraint on the public debt which takes the form of a soft borrowing constraint (SBC). In particular, the government has to pay a fine to a supranational institution whenever beginning of period debt $b_{t}$ exceeds a time-invariant reference value, denoted by $b^{\text {ref }}$. The debt-based criterion of the SGP could be interpreted as an example of such a SBC. The tightness of the SBC is governed by the policy parameter $\kappa$. Let the SBC be denoted

\footnotetext{
${ }^{9}$ For the ease of interpretation, the transaction costs are specified relative to GDP. Alternatively, they could be specified in terms of debt alone which however leaves all the results virtually unchanged.

${ }^{10}$ The presence of the transaction costs $\Phi_{t}$ in the household's budget constraint (2) does not alter the structure of the no-Ponzi-game condition. To see this, iterate forward (2) by successively eliminating $b_{t+1+j}$ and notice that $\Phi_{t}$ enters the budget constraint additively separable.
} 
by $f_{t}$, it is given by

$$
f_{t}=\kappa\left(b_{t}-b^{r e f}\right) I\left[b_{t} ; b^{r e f}\right]
$$

where the indicator function is given by

$$
I\left[b_{t} ; b^{r e f}\right]=\left\{\begin{array}{lll}
1 & \text { if } & b_{t}>b^{r e f} \\
0 & \text { if } & b_{t} \leq b^{r e f}
\end{array} .\right.
$$

The fine has only to be paid if the level of debt exceeds the reference value $b^{r e f}$. The government does not receive subsidies for levels of debt below $b^{\text {ref }}$. The SBC allows for transitory as well as permanent deviations from $b^{\text {ref }}$. For $\kappa \rightarrow \infty$ the SBC converges to a balanced budget rule. The policy parameters $\kappa$ and $b^{\text {ref }}$ are treated as if controlled by the supranational institution, like in case of the SGP. They are taken as given by the government. The aim of the following analysis is to assess the effects of the SBC and to determine the optimal values of $\kappa$ and $b^{r e f}$. The government budget constraint reads

$$
g_{t}+b_{t}=\frac{b_{t+1}}{R_{t}}+\tau_{t} w_{t} n_{t}-f_{t}
$$

Since the fine payments are assumed to be made to the supranational institution, they are resource costs to the economy. ${ }^{11}$ The resource constraint of the economy is given by

$$
y_{t}=c_{t}+g_{t}+f_{t}
$$

Now, for a given government policy (which will be determined in detail below), a competitive equilibrium can be defined as follows:

Definition 1. For a given government policy $\left\{b_{t}, \tau_{t}\right\}_{t=0}^{\infty}$ satisfying the government budget constraint (8), a competitive equilibrium is a set of sequences $\left\{c_{t}, n_{t}, f_{t}, R_{t}, w_{t}, y_{t}, \Phi_{t}, \pi_{t}\right\}_{t=0}^{\infty}$ satisfying (3)- (6), (9), $y_{t}=a_{t} n_{t}, w_{t}=a_{t}, \Phi_{t}=\pi_{t}$, and the transversality condition for given exogenous processes $\left\{a_{t}, g_{t}\right\}_{t=0}^{\infty}$ and an initial value $b_{0}$.

\subsection{Policy problem}

Fiscal policy in the majority of OECD countries over the last few decades points to a 'debt bias'. One possible reason for the debt bias is that governments may not be re-elected, and as a result may discount the future more heavily than the private sector. In order to account for this observation, I assume that the government is myopic, i.e. it has a smaller discount

\footnotetext{
${ }^{11}$ In Section 5, I discuss the alternative of introducing the fine at a national level (for example by changing the constitution by the required majority) and redistributing it to the household in a lump-sum way.
} 
factor than the households, but that it is otherwise benevolent and applies the instantaneous utility function of the households. The objective of the government is then given by

$$
E_{0} \sum_{t=0}^{\infty}(\gamma \beta)^{t} u\left(c_{t}, n_{t}\right),
$$

where $0<\gamma \leq 1$. Myopia can be interpreted as the result of an expected finite planning horizon of the incumbent government corresponding to the expected duration in power, following Grossman and Van Huyck (1988). In a quarterly model, the term $h=1 /[4(1-\gamma)]$ can then be interpreted as the expected planning horizon in years.

If $\gamma=1$, the objectives of the household and the government are identical (see 1 and 10) which gives the reference case of the fully benevolent Ramsey planner. If $\gamma<1$ the two objectives differ and the government is myopic. A discount factor of $\gamma \beta<\beta$ makes the issuance of new debt relatively attractive for the government since it would be willing to pay a higher interest rate than that demanded by the household, giving rise to a debt bias. This framework is convenient for the purpose of this paper because it allows staying conceptually close to the standard approach of the Ramsey planner which can then be used as a natural benchmark to assess the welfare effects of the SBC.

The politically optimal plan of the government can then be derived as follows:

Definition 2. To derive the politically optimal plan the government maximizes (10) over competitive equilibria by choosing sequences of tax rates $\tau_{t}$ and bonds $b_{t+1}$ subject to the government budget constraint (8), given an initial value $b_{0}$ and exogenous processes $\left\{a_{t}, g_{t}\right\}_{t=0}^{\infty}$.

There is a multiplicity of competitive equilibria indexed by different government policies. Definition 2 implies that the government picks the equilibrium which maximizes (10) and that the policy maker takes into account the existence of the SBC and the equilibrium reaction of the private sector.

To derive the politically optimal plan, I follow the methodology of the Ramsey primal approach. In particular, I derive a sequence of implementability constraints, following Aiyagari, Marcet, Sargent, and Seppälä (2002). To start, I substitute out prices $R_{t}$ and $w_{t}$ and taxes $\tau_{t}$ in the household's budget constraint (2) by using the household's first order conditions (4) and (5), which yields

$$
c_{t}+b_{t+1}\left[\beta E_{t} \frac{u_{c, t+1}}{u_{c, t}}-\phi \frac{b_{t+1}}{y_{t}}\right]=\frac{-u_{n, t} n_{t}}{u_{c, t}}+b_{t},
$$

where I used that $\Phi_{t}=\pi_{t}$. Now, I iterate forward (11), apply the law of iterated expectations, 
and use the transversality condition, yielding ${ }^{12}$

$$
u_{c, t} b_{t}=E_{t} \sum_{j=0}^{\infty} \beta^{j} u_{c, t+j}\left[c_{t+j}+\frac{u_{n, t+j} n_{t+j}}{u_{c, t+j}}-\phi \frac{b_{t+1+j}^{2}}{y_{t+j}}\right] .
$$

Incomplete markets imply that at the end of each period the government has to form new expectations, depending on the realization of shocks today, of the future state of the economy. This in turn implies that the price of debt $R_{t}$ as well as the expected present value of the budget surplus depends on the formed expectations and the realization of shocks today. ${ }^{13}$

The reaction of the private sector to the government's policy is summarized by (12). Using (6) and $y_{t}=a_{t} n_{t}$, the resource constraint of the economy reads

$$
a_{t} n_{t}=c_{t}+g_{t}+\kappa\left(b_{t}-b^{r e f}\right) I\left[b_{t} ; b^{r e f}\right] .
$$

Equations (12) and (13) summarize the restrictions on the set of allocations the government can achieve. ${ }^{14}$

Let $\eta_{t}$ and $\alpha_{t}$ denote the Lagrange multipliers on the resource and implementability constraints, respectively. The policy maker maximizes (10) s.t. (12) and (13):

$$
\begin{aligned}
\mathcal{L}= & E_{0} \sum_{t=0}^{\infty}(\gamma \beta)^{t}\left\{u\left(c_{t}, n_{t}\right)\right. \\
& +\eta_{t}\left(a_{t} n_{t}-c_{t}-g_{t}-\kappa\left(b_{t}-b^{r e f}\right) I\left[b_{t} ; b^{r e f}\right]\right) \\
& \left.+\alpha_{t}\left(E_{t} \sum_{j=0}^{\infty} \beta^{j} u_{c, t+j}\left[c_{t+j}+\frac{u_{n, t+j} n_{t+j}}{u_{c, t+j}}-\phi \frac{b_{t+1+j}^{2}}{a_{t+j} n_{t+j}}\right]-u_{c, t} b_{t}\right)\right\} .
\end{aligned}
$$

Since the problem in (14) exhibits a discontinuity due to the presence of the indicator function $I\left[b_{t} ; b^{r e f}\right]$, I approximate the indicator function with a continuous transition function which allows applying standard local approximation methods. ${ }^{15}$ In particular, I use the logistic

\footnotetext{
${ }^{12}$ For a derivation of the sequence of implementability constraints see Appendix A.

${ }^{13}$ In the case of complete markets, the debt payoff can be conditioned on the state of the economy such that the present value of the future surplus across different current states is known in advance and might differ across current states. This flexibility of the contract between the government and the household implies that it is possible to reduce the set of constraints in (12) to one single implementability constraint as of period zero. In other words, under complete markets the government can construct a state contingent plan which ensures solvency as of period zero. Under incomplete markets instead, the government has to adjust its plan, i.e. the present value of the surplus, each period in response to the realized state of the economy such as to ensure solvency.

${ }^{14}$ The intertemporal budget constraint of the government, including the requirement that the discounted value of debt at infinity be non-positive, is satisfied by Walras' Law.

${ }^{15}$ Moreover, a continuous transition function seems to be in accordance with reality where strict constraints usually do not exist. Consider, for example, the case of a debt contract. Usually, it is always possible to find some lender, no matter what the existing level of debt of the borrower or its capacity to pay-back the new debt are. To find such a lender is just a question of the size of the offered interest rate in the contract (which
} 
function, which has been used in, for example, Bayoumi, Goldstein, and Woglom (1995) to model nonlinearities:

$$
L_{t} \equiv L_{t}\left(\delta, b_{t}, b^{r e f}\right)=\frac{1}{1+\exp \left(-\delta\left(b_{t}-b^{r e f}\right)\right)}, \quad \delta>0
$$

with $L_{t}>0$ and $\frac{\partial L_{t}}{\partial b_{t}}>0$. For $\delta \rightarrow \infty, L_{t}\left(\delta, b_{t}, b^{r e f}\right) \rightarrow I\left[b_{t} ; b^{r e f}\right]$.

Since the infinite double sum in (14) complicates the analysis of the policy problem, I rewrite the Lagrangian recursively, following Aiyagari, Marcet, Sargent, and Seppälä (2002). I define a new stochastic multiplier $\mu_{t}=\mu_{t-1} / \gamma+\alpha_{t}$, where $\mu_{-1}=0$. The infinite double sum can then be written recursively as ${ }^{16}$

$$
E_{0} \sum_{t=0}^{\infty}(\gamma \beta)^{t} \alpha_{t} E_{t} \sum_{j=0}^{\infty} \beta^{j} s_{t+j}=E_{0} \sum_{t=0}^{\infty}(\gamma \beta)^{t} \mu_{t} s_{t},
$$

where $s_{t+j} \equiv u_{c, t+j}\left(c_{t+j}+\frac{u_{n, t+j} n_{t+j}}{u_{c, t+j}}-\phi \frac{b_{t+j+1}^{2}}{a_{t+j} n_{t+j}}\right)$. Using (15) and (16), the Lagrangian in (14) can be written as

$$
\begin{aligned}
\mathcal{L}= & E_{0} \sum_{t=0}^{\infty}(\gamma \beta)^{t}\left\{u\left(c_{t}, n_{t}\right)\right. \\
& +\eta_{t}\left[a_{t} n_{t}-c_{t}-g_{t}-\kappa\left(b_{t}-b^{r e f}\right) L_{t}\right] \\
& \left.+\mu_{t}\left[u_{c, t} c_{t}+u_{n, t} n_{t}-u_{c, t}\left(\phi \frac{b_{t+1}^{2}}{a_{t} n_{t}}+b_{t}\right)\right]+\frac{\mu_{t-1}}{\gamma} b_{t} u_{c, t}\right\} .
\end{aligned}
$$

The first order conditions to (17) w.r.t. $c_{t}, n_{t}$, and $b_{t+1}$ are

$$
\begin{aligned}
\eta_{t} & =u_{c, t}+\mu_{t}\left[u_{c c, t} c_{t}+u_{c, t}-u_{c c, t}\left(\phi \frac{b_{t+1}^{2}}{a_{t} n_{t}}+b_{t}\right)\right]+\frac{\mu_{t-1}}{\gamma} b_{t} u_{c c, t} \\
0 & =u_{n, t}+\eta_{t} a_{t}+\mu_{t}\left(u_{n n, t} n_{t}+u_{n, t}+u_{c, t} \phi \frac{b_{t+1}^{2}}{a_{t} n_{t}^{2}}\right) \\
0 & =\mu_{t} u_{c, t} \frac{2 \phi b_{t+1}}{a_{t} n_{t}}+\gamma \beta E_{t}\left(\eta_{t+1} \frac{\partial\left[\kappa\left(b_{t+1}-b^{r e f}\right) L_{t+1}\right]}{\partial b_{t+1}}+\mu_{t+1} u_{c, t+1}-\frac{\mu_{t}}{\gamma} u_{c, t+1}\right),
\end{aligned}
$$

where

$$
\frac{\partial\left[\kappa\left(b_{t+1}-b^{r e f}\right) L_{t+1}\right]}{\partial b_{t+1}}=\kappa L_{t+1}\left(1+\delta\left(b_{t+1}-b^{r e f}\right) e^{-\delta\left(b_{t+1}-b^{r e f}\right)} L_{t+1}\right)
$$

Now, an equilibrium under the politically optimal plan can be defined as follows:

may indeed by a highly non-linear function in the level of debt or the capacity to pay-back that debt).

${ }^{16}$ For a derivation of (16) see Appendix B. 
Definition 3. An equilibrium under the politically optimal plan is a set of sequences $\left\{b_{t}, c_{t}\right.$, $\left.n_{t}, \eta_{t}, \mu_{t}\right\}_{t=0}^{\infty}$ satisfying (11), (13) with $I\left[b_{t} ; b^{r e f}\right] \approx L_{t}$, and (18)- (20) for given exogenous processes $\left\{a_{t}, g_{t}\right\}_{t=0}^{\infty}$ and initial values $b_{0}$ and $\mu_{-1}=0$.

For $\gamma=1$, Definition 3 implies the optimal policy of the Ramsey planner. For $\gamma<1$, fiscal policy is still optimizing but optimization occurs with respect to the policy maker's own objective. In the following analysis, I refer to the case of $\gamma=1$ as Ramsey-optimal policy and to the case of $\gamma<1$ as myopic fiscal policy. In both cases, the government adheres to commitments made in the past when choosing policy (see, for example, Chari and Kehoe, 1999).

\subsection{Equilibrium and steady state analysis}

In this subsection, I analyze the equilibrium properties under Ramsey-optimal policy and myopic fiscal policy in order to show the main differences between the two regimes and to illustrate the effects of the transaction costs and the SBC. The non-stochastic steady state is defined as the long-run equilibrium in absence of shocks and where all endogenous variables grow with a constant rate equal to zero. I drop the time subscript of a variable to denote its non-stochastic steady state, henceforth.

First, I illustrate the effects of $\gamma$ and $\phi$ in the model without SBC, i.e. where $\kappa=0$. In (20) we see how the policy maker equates the budget relaxing effect of issuing new debt to the associated higher expected fine and transaction costs. For the case of Ramsey-optimal policy and $\phi=0$ (and $\kappa=0$ ) equation (20) indicates the existence of a unit root as in Barro (1979):

$$
\mu_{t} u_{c, t+1}=E_{t}\left[\mu_{t+1} u_{c, t+1}\right]
$$

Equation (22) shows that under incomplete markets and no transaction costs the allocation and in particular welfare depend on initial conditions and not only on policy. To remove the unit root from the system, I thus assume that $\phi>0$. Then, the non-stochastic steady state is independent of initial conditions and it is possible to compare welfare under the different regimes.

Next, I consider the case of myopic fiscal policy and $\phi>0$ (while $\kappa=0$ throughout). Then, (20) can be used to illustrate the effect of $\gamma$ and $\phi$ on the level of debt. In the non-stochastic steady state it implies

$$
\frac{b}{y}=\frac{(1-\gamma) \beta}{2 \phi}
$$


For $\gamma=1 \Rightarrow b / y=0$ which gives the reference case of Ramsey-optimal policy with zero debt. If $\gamma<1 \Rightarrow b / y>0$. Myopia leads the government to cut taxes and issue debt. This policy continues until the increase in transaction costs and the associated rise of the interest rate close the gap between the discount factors of the government and the household. In the long run this policy leads to a positive level of debt. ${ }^{17}$ For $\phi \rightarrow 0 \Rightarrow b / y \rightarrow \infty$. Without the SBC, $b / y$ is thus determined by the size of $\gamma$ and $\phi$. Accordingly, the second purpose of $\phi>0$ (next to the elimination of the unit root) is to ensure a well defined steady state under myopic fiscal policy without SBC by preventing the path of debt to be explosive.

Now, I analyze the effects of the SBC, i.e. $\kappa>0$. For the case of myopic fiscal policy under a SBC (and keeping $\phi>0$ ), in the non-stochastic steady state (20) implies

$$
\frac{b}{y}=\frac{(1-\gamma) \beta}{2 \phi}-\frac{1}{2 \phi}\left(\frac{\gamma \beta \eta}{\mu u_{c}}\right) \frac{\partial\left[\kappa\left(b-b^{r e f}\right) L\right]}{\partial b}
$$

The second term on the RHS gives the effect of the SBC on $b / y$. Given that $\kappa>0$, $\frac{\partial\left[\kappa\left(b-b^{r e f}\right) L\right]}{\partial b}>0$ for $b>b^{r e f}$. Moreover, $\left(\frac{\gamma \beta \eta}{\mu u_{c}}\right)>0$ since marginal utility $u_{c}$ and the Lagrange multipliers $\eta$ and $\mu$ are strictly positive for binding resource and implementability constraints. Hence, (23) shows that the introduction of the SBC tends to reduce $b / y$.

Finally, I consider the case of $\kappa>0$ and no transaction costs, i.e. $\phi=0$. Equation (20) implies

$$
E_{t}\left[\eta_{t+1} \frac{\partial\left[\kappa\left(b_{t+1}-b^{r e f}\right) L_{t+1}\right]}{\partial b_{t+1}}+\mu_{t+1} u_{c, t+1}-\frac{\mu_{t}}{\gamma} u_{c, t+1}\right]=0,
$$

and in steady state

$$
\eta \frac{\partial\left[\kappa\left(b-b^{r e f}\right) L\right]}{\partial b}=\mu u_{c}\left(\frac{1}{\gamma}-1\right)
$$

Even for $\gamma=1$, the first equation shows that the SBC ensures independence of initial conditions by removing the unit root from the system. The second equation implicitly gives the level of debt in steady state and indicates that the introduction of the SBC rules out explosive paths of debt. However, to be able to numerically compare welfare under myopic fiscal policy before and after the introduction of the SBC, I maintain the assumption of positive transaction costs throughout the analysis.

Now, I turn to an interpretation of (18). To simplify the comparison between the two regimes, I consider the case of log-utility here. Then, in the non-stochastic steady state (18)

\footnotetext{
${ }^{17}$ With positive debt in steady state fiscal policy needs to generate surpluses in order to finance permanent interest payments. This is the reason why I do not consider a deficit criterion in this model.
} 
implies

$$
\eta=\frac{1}{c}+\left(1-\frac{1}{\gamma}\right) \mu \frac{b}{c^{2}}+\mu \frac{\phi b^{2}}{c^{2} a n}
$$

with $0 \leq \gamma \leq 1$. Equation (24) provides information on $\eta$ which measures in terms of utility the value attributed to a relaxation of the resource constraint in the long run. For the limiting case of $\phi \rightarrow 0$ the last term on the RHS vanishes. Under Ramsey-optimal policy $\gamma=1$ and (24) reads $\eta=\frac{1}{c}=u_{c}$. Relaxations of the budget and the resource constraint are valued identically by the household and the policy maker. Under myopic fiscal policy $\gamma<1$ which implies that $\left(1-\frac{1}{\gamma}\right)<0$ so that $\eta<u_{c}$ (given that $b, c, \mu>0$ ). This inequality implies that, due to myopia, a relaxation of the resource constraint in the long run is valued less by the policy maker than a relaxation of the budget constraint by the household.

\section{Calibration and welfare measure}

\subsection{Calibration}

This subsection describes the baseline calibration of the model. All parameters are calibrated to a quarterly frequency. Government spending $g_{t}$ and productivity $a_{t}$ are assumed to follow independent stationary $\mathrm{AR}(1)$ processes in their logarithms

$$
\begin{aligned}
& \ln g_{t}=\left(1-\rho^{g}\right) \ln \bar{g}+\rho^{g} \ln g_{t-1}+\varepsilon_{t}^{g} \\
& \ln a_{t}=\rho^{a} \ln a_{t-1}+\varepsilon_{t}^{a},
\end{aligned}
$$

where $\varepsilon_{t}^{g}$ and $\varepsilon_{t}^{a}$ are n.i.d. with mean zero. Following Schmitt-Grohé and Uribe (2007), the standard deviations of the innovations are $\sigma_{\varepsilon^{g}}=0.016$ and $\sigma_{\varepsilon^{a}}=0.0064$ and $\rho^{g}=\rho^{a}=0.9$.

I set the expected planning horizon of the government $h$ to twelve years. This value corresponds to three legislative periods and is supposed to loosely reflect the time in office of an average member of the executive authority. From $h=1 /[4(1-\gamma)]$ it implies a value of $\gamma=0.979$. The single period utility function is of the form

$$
u\left(c_{t}, n_{t}\right)=\frac{c_{t}^{1-\sigma}-1}{1-\sigma}-\frac{\nu n_{t}^{1+\varphi}}{1+\varphi}
$$

The weight for working time in utility is $\nu=4$ and $\sigma$ and $\varphi$ are set to unity. These values imply an equal division of the total time endowment into working time and leisure, for convenience. In Section 5.2, I discuss alternative values for $\sigma$ and $\varphi$. The household's discount factor is $\beta=0.99$. 
In order to try replicating Ramsey-optimal policy where debt is zero in steady state (see Section 2.4), I set the reference value of debt in the SBC to $b^{r e f}=0$ in most of the analysis. Hence, while the structure of the proposed SBC reflects features of the SGP, its calibration is stricter than the $60 \%$ debt-to-GDP criterion of the SGP and sets a lower reference value of debt, as suggested by the theoretically optimal fiscal policy. To assess the effectiveness of the SBC, the policy parameter $\kappa$ varies between 0 an 0.016 . Given a steady state value of $y=n=0.5$, the upper bound implies a fine of about $3 \%$ of GDP per unit of debt exceeding $b^{r e f}$. The parameter governing the size of the transaction costs $\phi$ is set to 0.01 . In steady state, this value implies an increase of the interest rate (which equals $R=1.02073$ under myopic fiscal policy) of about four basis points on an annual basis when $b / y$ increases by one percent. It is well within the estimates for the effect of debt on the government's borrowing costs (see Gale and Orszag, 2003, Engen and Hubbard, 2004, or Laubach, 2009). The parameter in the logistic function is set to $\delta=300$ which gives a smooth approximation of the indicator function, as shown by Franses and van Dijk (2000). The value of government consumption $\bar{g}$ is set to 0.1 such as to obtain a ratio of $\bar{g} / y=0.2$ under Ramsey-optimal policy, corresponding to the average share of government consumption in GDP in the OECD countries (see OECD, 2009b). In Section 5, I discuss the alternative of fixing the ratio $\overline{g / y}$ instead of the absolute value of $\bar{g}$ itself. Table 1 summarizes the parameter values of the baseline calibration.

Table 1: Parameter values of the baseline calibration to a quarterly frequency.

\begin{tabular}{lll}
\hline \hline Parameter & Value & Description \\
\hline$\beta$ & 0.99 & Household discount factor \\
$\gamma$ & {$[0.979 ; 1]$} & Myopia \\
$\nu$ & 4 & Weight of labour in utility \\
$\sigma$ & 1 & Inverse intertemporal elasticity of substitution \\
$\varphi$ & 1 & Inverse Frisch labor supply elasticity \\
$\rho^{g}$ & 0.9 & Serial correlation government consumption \\
$\rho^{a}$ & 0.9 & Serial correlation productivity \\
$\sigma_{\varepsilon^{g}}$ & 0.016 & St. dev. of innovation to gov. consumption \\
$\sigma_{\varepsilon^{a}}$ & 0.0064 & St. dev. of innovation to productivity \\
$\bar{g} / y$ & 0.2 & Government consumption to GDP \\
$\kappa$ & {$[0 ; 0.016]$} & Tightness of the SBC \\
$b^{r e f}$ & 0 & Reference value of debt in the SBC \\
$\phi$ & 0.01 & Transaction cost parameter \\
$\delta$ & 300 & Smoothness of the logistic function \\
\hline \hline
\end{tabular}




\subsection{Welfare measure}

Since the steady state of the economy depends on policy, I use two methods to compute the welfare effects of myopic fiscal policy and the SBC. The first method considers pure shifts of the steady state of the economy, while the second method accounts for the period of transition between these. In both cases welfare is based on the representative household's utility. Following Jonsson and Klein (2003), in the first case welfare is measured as expected lifetime utility while in the second case it is measured as lifetime utility under perfect foresight.

\subsubsection{Welfare under uncertainty}

The first measure illustrates the size of welfare effects associated with pure shifts of both the stochastic and non-stochastic steady state under each regime. To start, I define the variable

$$
V_{t} \equiv E_{t} \sum_{j=0}^{\infty} \beta^{j} u\left(c_{t+j}, n_{t+j}\right) .
$$

Following Schmitt-Grohé and Uribe (2007) and based on household utility (see 1), I then define welfare under Ramsey-optimal policy, denoted by $R$, conditional on the state of the economy in period $j=0$ being the non-stochastic steady state associated with that regime and remaining under that regime forever as

$$
V^{R}=E_{t} \sum_{j=0}^{\infty} \beta^{j} u\left(c_{t+j}^{R}, n_{t+j}^{R}\right),
$$

where $c_{t+j}^{R}$ and $n_{t+j}^{R}$ denote the particular plans for consumption and working time under regime $R$. In the same way, I define welfare under myopic fiscal policy, denoted by $M$, as

$$
V^{M}=E_{t} \sum_{j=0}^{\infty} \beta^{j} u\left(c_{t+j}^{M}, n_{t+j}^{M}\right),
$$

where now $c_{t+j}^{M}$ and $n_{t+j}^{M}$ are functions of myopia $\gamma$.

Now, let $\lambda^{M}$ denote welfare costs of myopic fiscal policy in terms of consumption. It is defined as the fraction of the Ramsey consumption process that a household would be willing to give up to be as well off under policy $M$ as under policy $R$ :

$$
V^{M}=E_{t} \sum_{j=0}^{\infty} \beta^{j} u\left(\left(1-\lambda^{M}\right) c_{t+j}^{R}, n_{t+j}^{R}\right) .
$$


Using (25) with $\sigma=1, \varphi=1$, and $\nu=4$ and rearranging terms yields

$$
\begin{aligned}
V^{M} & =E_{t} \sum_{j=0}^{\infty} \beta^{j}\left(\log \left[\left(1-\lambda^{M}\right) c_{t+j}^{R}\right]-2\left(n_{t+j}^{R}\right)^{2}\right) . \\
& =E_{t} \sum_{j=0}^{\infty} \beta^{j}\left(\log \left(1-\lambda^{M}\right)+\log c_{t+j}^{R}-2\left(n_{t+j}^{R}\right)^{2}\right) \\
& =\frac{\log \left(1-\lambda^{M}\right)}{1-\beta}+V^{R}
\end{aligned}
$$

Solving for $\lambda^{M}$ gives

$$
\lambda^{M}=1-\exp \left[\left(V^{M}-V^{R}\right)(1-\beta)\right] .
$$

To compute $\lambda^{M}$, I use the approximated policy functions for $V^{M}$ and $V^{R}$. In particular, the solution to the system of equations of Definition 3 and (26) gives $V_{t}$ as a function of endogenous and exogenous state variables $x_{t}$ and a parameter scaling the standard deviations of the exogenous shocks $\omega: V\left(x_{t}, \omega\right)$ (see Schmitt-Grohé and Uribe, 2004). Using perturbation methods, a second-order approximation to $V_{t}$ around the non-stochastic steady state, denoted by $\bar{x}$, yields

$$
\begin{aligned}
V\left(x_{t}, \omega\right) \approx & V(\bar{x}, 0)+V_{x}(\bar{x}, 0)\left(x_{t}-\bar{x}\right)+V_{\omega}(\bar{x}, 0) \omega+V_{x \omega}(\bar{x}, 0) \omega\left(x_{t}-\bar{x}\right) \\
& +\frac{1}{2} V_{x x}(\bar{x}, 0)\left(x_{t}-\bar{x}\right)^{2}+\frac{1}{2} V_{\omega \omega}(\bar{x}, 0) \omega^{2},
\end{aligned}
$$

where $V_{x}$ and $V_{x x}$ denote the first and second derivative w.r.t $x_{t}$, respectively, and where I used that in the non-stochastic steady state $\omega=0$. To compute welfare, I evaluate $V\left(x_{t}, \omega\right)$ assuming that the initial state $x_{0}$ is equal the non-stochastic steady state $\bar{x}$, i.e. $x_{0}=\bar{x}$ and $\omega=0$ :

$$
V=V\left(x_{0}, 0\right) \approx V(\bar{x}, 0)+V_{\omega}(\bar{x}, 0) \omega+\frac{1}{2} V_{\omega \omega}(\bar{x}, 0) \omega^{2} .
$$

Schmitt-Grohé and Uribe (2004) show that certainty equivalence also holds for a first-order approximation when using perturbation methods which implies that $V_{\omega}(\bar{x}, 0)=0$, yielding

$$
V\left(x_{0}, 0\right) \approx V(\bar{x}, 0)+\frac{1}{2} V_{\omega \omega}(\bar{x}, 0) \omega^{2} .
$$

Up to first order accuracy, welfare is given by its non-stochastic steady state value $V(\bar{x}, 0)$, as can be seen from the RHS of (32). The second term on the RHS of (32) gives the shift of the level of $V\left(x_{0}, 0\right)$ due to uncertainty and hence gives the difference between the nonstochastic and the stochastic steady state of that variable. The size of the shift depends on 
$\omega$ which in turn depends on the standard deviation of the innovations to factor productivity and government consumption, as calibrated in Section 3.1.

Finally, to obtain $\lambda^{M}$, I evaluate $V^{M}\left(x_{t}, \omega\right)$ and $V^{R}\left(x_{t}, \omega\right)$ in the state of the economy in period $j=0$ being the non-stochastic steady state associated with the respective regime, yielding $V^{M}$ and $V^{R}$. Identical non-stochastic steady states imply that $V^{M}(\bar{x}, 0)=V^{R}(\bar{x}, 0)$. This is the case in the analysis of Section 4.3 where only business cycle effects are considered. To obtain the first and second order approximations to the policy functions, I use the software package Dynare 4.1 for MATLAB. ${ }^{18}$

\subsubsection{Welfare under perfect foresight}

It takes time for the economy to move from one steady state to another and the measure in (31) neglects welfare effects during this period of transition. Therefore, I use a second method to measure welfare which accounts for the transitional period. To give a preview, using (31) I find that more than $99.8 \%$ of the welfare costs of myopic fiscal policy are due to a distorted non-stochastic steady state (see Section 4.1). Following Jonsson and Klein (2003), the second method thus considers only welfare effects under perfect foresight.

I define welfare under regime $R$ as the discounted sum of household period utility under perfect foresight conditional on the state of the economy in period $j=0$ being the nonstochastic steady state associated with that regime and staying there forever:

$$
W^{R}=\sum_{j=0}^{\infty} \beta^{j} u\left(c_{t+j}^{R}, n_{t+j}^{R}\right),
$$

where $c_{t+j}^{R}$ and $n_{t+j}^{R}$ denote consumption and working time under policy $R$. Welfare under a transition from the superior regime $R$ to the inferior regime $M$ is then simply defined as the discounted sum of household period utility conditional on the state of the economy in period $j=0$ being the non-stochastic steady state associated with regime $R$, changing permanently to regime $M$ in period $j=1$, and taking into account the period of transition:

$$
W^{R M}=\sum_{j=0}^{\infty} \beta^{j} u\left(c_{t+j}^{R M}, n_{t+j}^{R M}\right),
$$

where $c_{t+j}^{R M}$ and $n_{t+j}^{R M}$ denote consumption and working time under this scenario. Then, welfare costs $\Lambda^{R M}$ (in terms of consumption under regime $R$ ) associated with a permanent change from regime $R$ to regime $M$ are defined as in (30) but for the case of perfect foresight.

\footnotetext{
${ }^{18}$ The software package is available at http://www.dynare.org.
} 
For the given utility function they are given by

$$
\Lambda^{R M}=1-\exp \left[\left(W^{R M}-W^{R}\right)(1-\beta)\right]
$$

To obtain $W^{R M}$, I exogenously change $\gamma$ from $\gamma=1$ to $\gamma=0.979$ in period $j=1$ and compute the deterministic path of transition between the two regimes, using Dynare 4.1.

\section{Numerical analysis of the soft borrowing constraint}

In this section, I analyze the effects of the SBC on welfare under the following four scenarios: (i) A shift, due to myopic fiscal policy and relative to Ramsey-optimal policy, of both the non-stochastic steady state and the stochastic steady state, neglecting the period of transition, (ii) a debt accumulating transition under perfect foresight from the steady state under Ramsey-optimal policy to the steady state under myopic fiscal policy without SBC, (iii) a debt consolidating transition under perfect foresight, induced by the introduction of the SBC, from the steady state under myopic fiscal policy without SBC to the steady state under myopic fiscal policy with SBC, and (iv) short run welfare costs of myopic fiscal policy with SBC relative to Ramsey-optimal policy.

\subsection{Long run effects of myopia and the soft borrowing constraint}

In this first scenario, I analyze the long run welfare effects of the SBC by first setting $\kappa=0$ and computing welfare costs of myopic fiscal policy without SBC. Then, I introduce the SBC by setting $\kappa>0$ and show that this enhances welfare.

\subsubsection{Myopic fiscal policy without SBC: $\kappa=0$}

This subsection presents results closely related to Kumhof and Yakadina (2007). These results illustrate the effects of myopia before the introduction of the SBC, i.e. here I set $\kappa=0$. Figure 1 depicts the steady states of the model's key variables for different values of myopia $\gamma$. In particular, $\gamma$ varies between 0.979 (the value implied by the baseline calibration of a planning horizon of twelve years) and 1 (which implies Ramsey-optimal policy as $h \rightarrow \infty$ ).

The upper left panel shows welfare costs as defined in (31) and expressed as percentage: $\lambda^{M} \times 100$. As myopia increases welfare costs amount up to $0.353 \%$ of the Ramsey-optimal consumption stream. The solid line shows welfare costs when $V^{M}$ and $V^{R}$ are approximated up to first-order accuracy while the circles depict the approximation up to second-order 

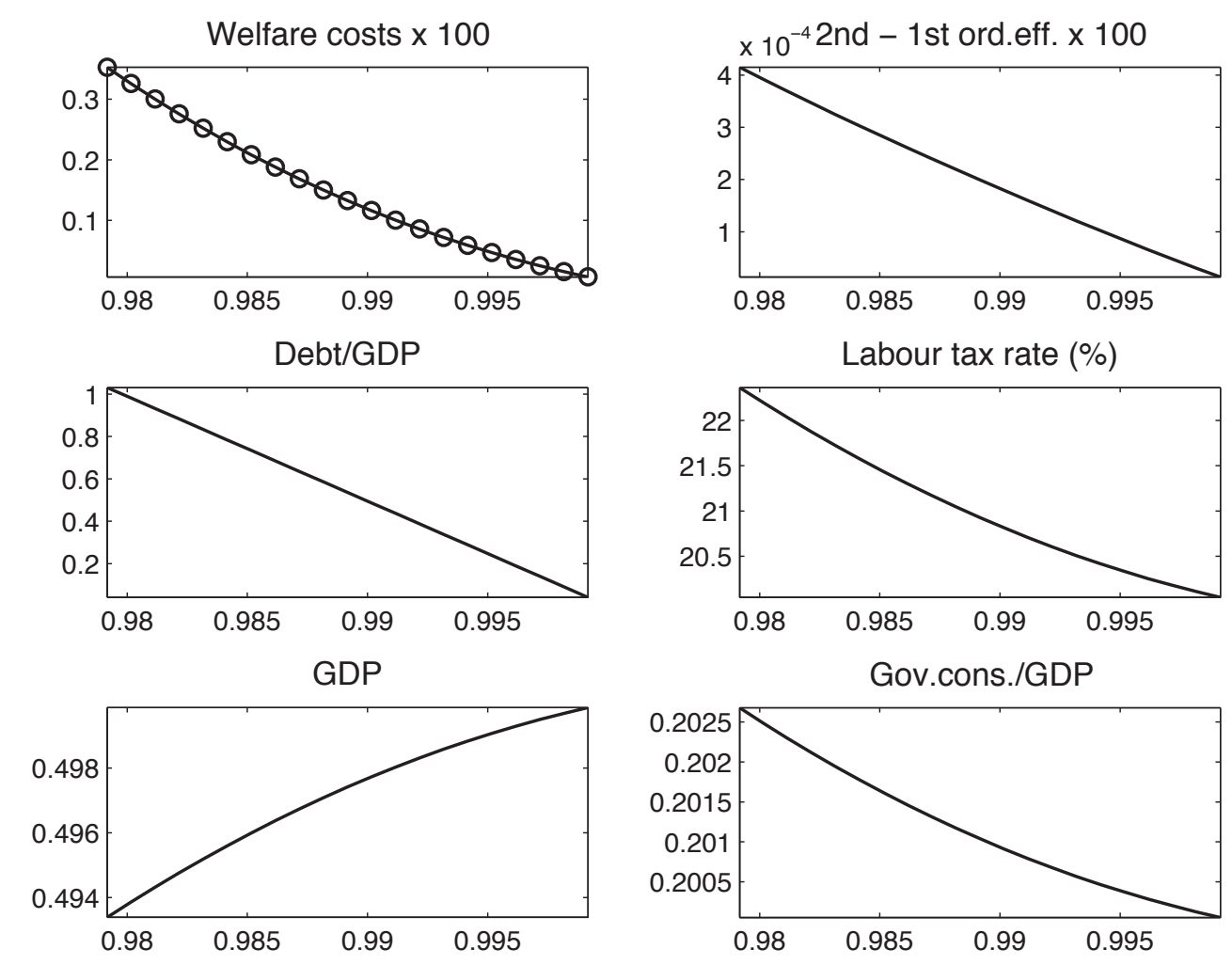

Figure 1: Effects of myopia on the steady state: $\gamma \in[0.979,1]$. Upper left panel: solid line non-stochastic steady state, circles - stochastic steady state.

accuracy. The two lines are virtually identical for the considered range of $\gamma$. The upper right panel depicts the difference between the two lines which increases as $\gamma$ decreases. However, for the given calibration and $\kappa=0.979$ the welfare costs due to a distorted stochastic steady state amount only to about $0.12 \%$ of total welfare costs. The utmost part of welfare costs, i.e. approximately $99.88 \%$, is due to a distorted non-stochastic steady state. The other panels thus concentrate on the non-stochastic steady state.

In the middle left panel we see how the ratio of debt to GDP increases as myopia increases. For $\gamma=0.979$ it amounts to $103 \%$. As can be seen from the middle right panel, labour taxes increase from $20 \%$ to about $22 \%$ to finance the permanently higher debt servicing costs as debt increases. Higher debt implies an increase of the interest rate. To illustrate that welfare costs are not only due to the increase of the interest rate, which is governed by the transaction cost parameter $\phi$, I compute $\lambda^{M}$ for the particular case of $\phi \rightarrow 0$. Holding the level of debt to GDP constant at the level implied by the baseline calibration, i.e. $b / y=1.03$, and letting $\gamma$ adjust endogenously, gives that for the limiting case of $\phi \rightarrow 0 \Rightarrow \lambda^{M} \rightarrow 0.162 \%$ (where I set $\phi=10^{-9}$ in the limit). Thus, in this particular case welfare costs are smaller as compared to 
the baseline calibration where $\lambda^{M}=0.353 \%$. This leads to an increase of the excess burden of taxation which reduces welfare. Higher tax rates depress working time and hence GDP (see lower left panel) and consumption. Since the level of government consumption is fixed, the ratio of government consumption to GDP increases.

In sum, a ratio of debt to GDP of $103 \%$ implies welfare costs of $0.353 \%$. Second order welfare costs are negligible, as in Lucas (2003). Using figures for quarterly per capita income in the Euro-zone in 2009 and a share of $60 \%$ of final consumption in GDP, total welfare costs amount to about $7,000 \times 0.6 \times 0.00353 \approx 15$ euros per person per quarter. These numbers provide the rationale for the subsequent analysis finding the optimal $\kappa$.

\subsubsection{Introducing the soft borrowing constraint: $\kappa>0$}

Now, I turn to an analysis of the long run welfare effects of the SBC by setting $\kappa>0$. The aim is to determine the value for $\kappa$ that reduces the long run level of debt and taxes, and hence welfare costs. I set the reference value of debt to $b^{r e f}=0$ in order to try replicating the non-stochastic steady state under Ramsey-optimal policy where $b=0$ (see Section 2.4 and Figure 1), yielding the following parameterization of the SBC:

$$
f_{t}=\kappa b_{t} L_{t}\left(\delta, b_{t}, b^{r e f}\right)=\kappa b_{t} L_{t}\left(300, b_{t}, 0\right)=\frac{\kappa b_{t}}{1+\exp \left(-300 b_{t}\right)} .
$$

Figure 2 shows the steady states of the debt to GDP ratio, the tax rate, and the associated welfare costs for different values of $\kappa \in[0,0.005]$, holding fixed $\gamma=0.979$. As $\kappa$ increases, welfare costs are reduced, as can be seen from the upper panel. As before, there is virtually no difference between first and second order approximations (depicted as a solid line and circles, respectively) to the policy functions of $V^{M}$ and $V^{R}$.

A value of $\kappa>0$ implies that the issuance of debt is associated with additional costs to the government which now has to pay a fine to the supranational institution for any $b>0$. These costs increase as $\kappa$ increases and induce a reduction of debt in steady state (see middle panel). In the lower panel we see that the tax rate can be reduced, and thus the deadweight loss, as steady state debt declines. The long run level of debt thus depends on the tightness of the SBC, i.e. on the value of $\kappa$. For the given calibration, $\kappa<0.003$ is not sufficient to completely prevent excessive borrowing. However, for $\kappa \geq 0.003$ the incentive to reduce debt due to the presence of the SBC outweighs the effect of myopia. In particular, for $\kappa=0.003$ the nonstochastic steady states under myopic fiscal policy under a SBC and under Ramsey-optimal policy are identical up to the third significant digit. This implies that $99.88 \%$ of the welfare 
Welfare costs $\times 100$

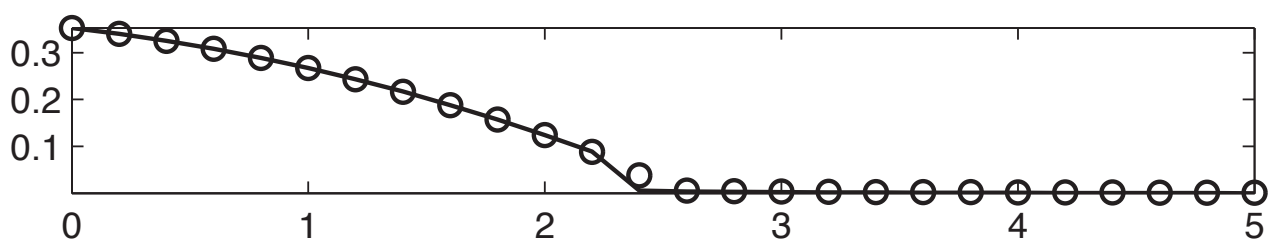

$x 10^{-3}$

Debt/GDP

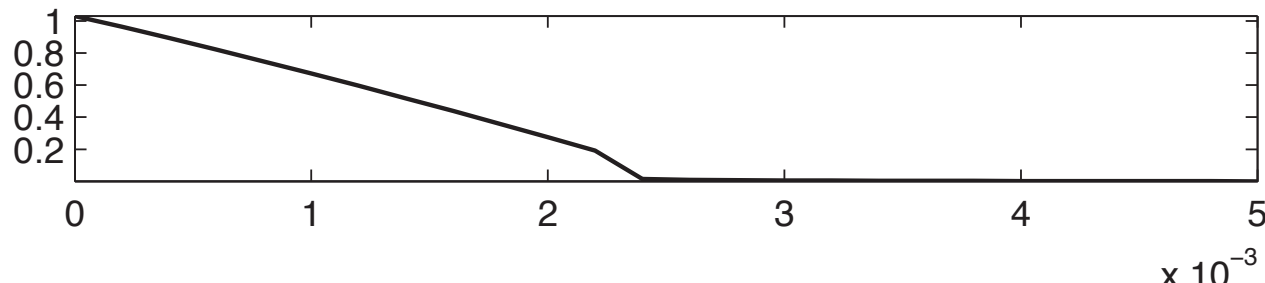

Labour tax rate $(\%)$

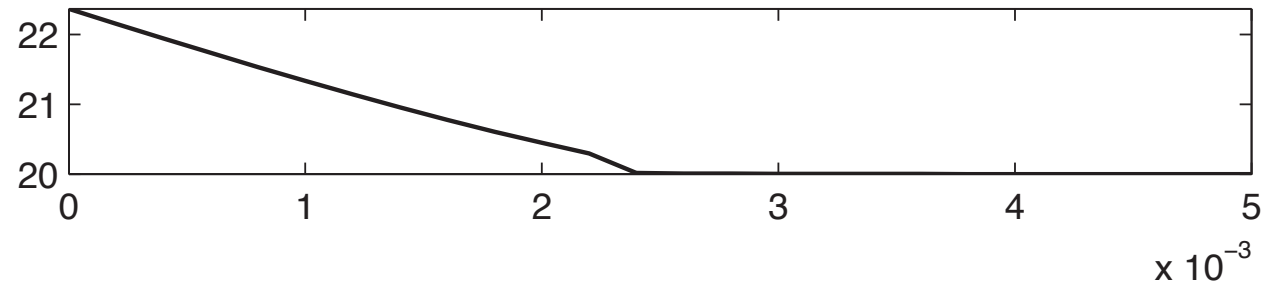

Figure 2: Effect of the tightness of the SBC on the steady state: $\kappa \in[0,0.005]$.

costs associated with myopic fiscal policy can be prevented. Since GDP in steady state is approximately $y=n \approx 0.5$, a value of $\kappa=0.003$ implies a fine on excessive debt of $0.6 \%$ of GDP per unit of debt exceeding $b^{\text {ref }}$. For any $\kappa \geq 0.003$ the steady state fine payments are zero because debt is at its reference value, i.e. $b=b^{r e f}=0$. In sum, the proposed $\mathrm{SBC}$ is an effective means to prevent excessive borrowing. It is possible to implement the same long run allocation as under Ramsey-optimal policy and thereby prevent the utmost part of the welfare costs of myopic fiscal policy.

\subsection{Transitional dynamics under a soft borrowing constraint}

Since it takes time for the economy to move from one steady state to another steady state, in this subsection I analyze how myopic fiscal policy and the SBC affect welfare when the period of transition is accounted for. I consider two scenarios: (i) A transition from Ramsey-optimal policy to myopic fiscal policy, and (ii) a transition from myopic fiscal policy without SBC to myopic fiscal policy under a SBC. The rationale for the analysis in (i) is to analyze the welfare consequences of myopic fiscal policy and the SBC with regard to the reference case of Ramsey- 
optimal policy when taking into account welfare effects during the debt accumulating period of transition. In (ii) the idea is to answer the following question: Given a level of debt to GDP of $103 \%$, does the introduction of the SBC and the induced reduction of debt outweigh the costs of higher tax rates during the period of consolidation? Since welfare costs of a distorted stochastic steady state amount only to $0.12 \%$ of total welfare costs (see previous subsection), I consider a transition under perfect foresight in both cases, following Jonsson and Klein (2003). For the computations, I set $T=5,000$.

\subsubsection{Preventing debt accumulation}

Figure 3 shows the debt accumulating transition from the steady state under Ramsey-optimal policy to the steady state under myopic fiscal policy. In period zero the economy operates under Ramsey-optimal policy with $\gamma=1$. This regime is replaced by myopic fiscal policy with $\gamma=0.979$ in periods $j=1, \ldots, T$.
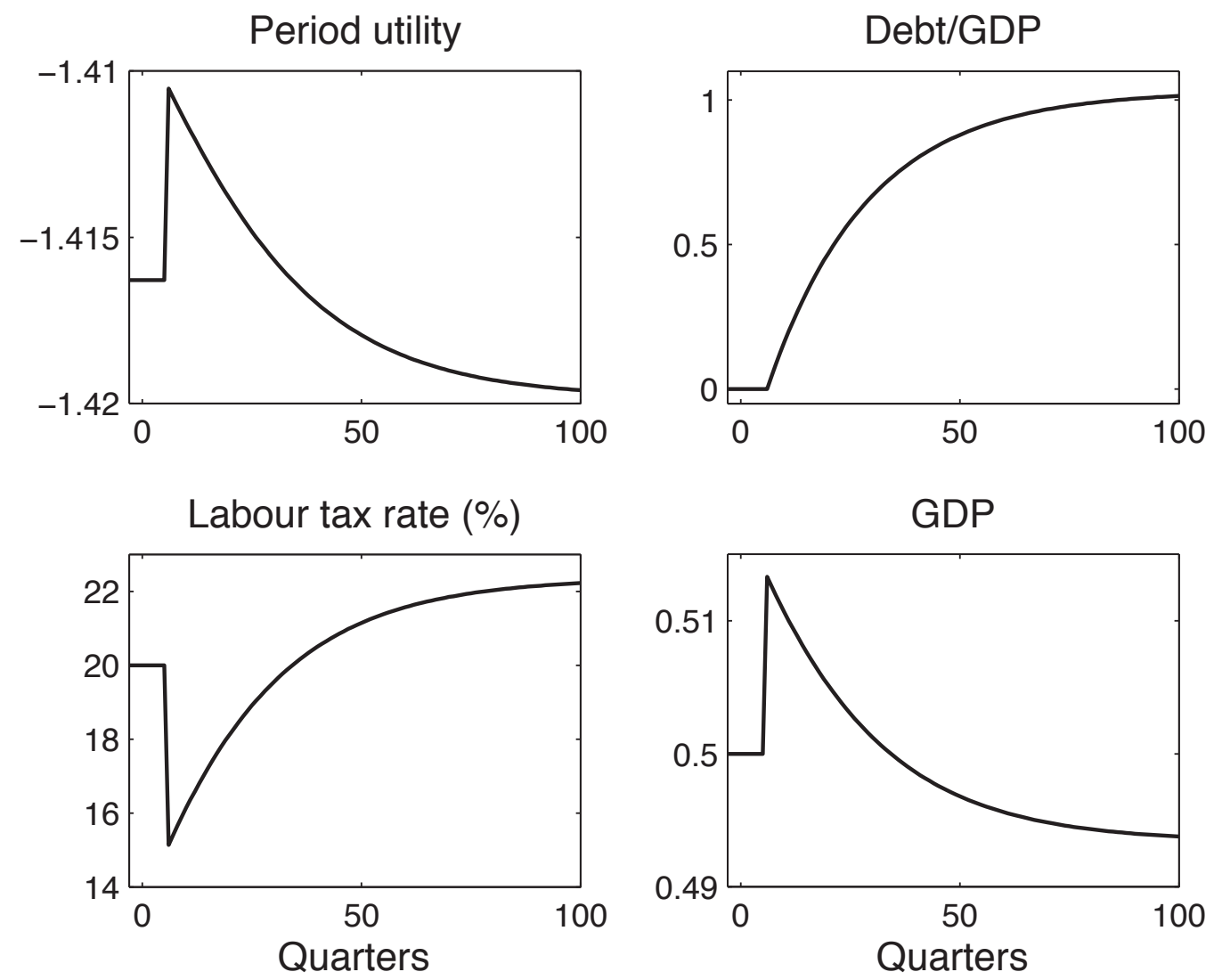

Figure 3: Transition under perfect foresight from the steady state under Ramsey-optimal policy (with $\gamma=1$ ) to the steady state under myopic fiscal policy (with $\gamma=0.979$ ).

As we can see from the figure, the transition is completed within about 25 years. At the 
beginning of the transition the government lowers tax rates and issues debt. This stimulates output and consumption and the household's period utility rises above its initial steady state for about 20 quarters. From then onwards, the tax rate is raised above its initial level to finance additional debt servicing costs as debt rises. In the long run, debt builds up to $103 \%$ of GDP.

The associated welfare costs of this transition under perfect foresight, as compared to staying under Ramsey-optimal policy, are defined in (33) and amount to

$$
\Lambda^{R M}=\left(1-\exp \left[\left(W^{R M}-W^{R}\right)(1-\beta)\right]\right)=0.141 \% .
$$

This value is about half of the welfare costs as measured in the previous subsection where $\lambda^{M}$ only considers steady state effects and does not account for the positive welfare effects in the first 20 quarters of the transitional period.

As the previous subsection showed, the long run level of debt is zero for $\kappa \geq 0.003$. Thus, by setting $\kappa \geq 0.003$ from period $j=0$ onwards the supranational institution can ensure that the economy remains in the steady state under Ramsey-optimal policy. ${ }^{19}$ There will be no transition to the steady state under myopic fiscal policy. Hence, in this scenario the introduction of the SBC avoids welfare losses of $0.141 \%$.

\subsubsection{Debt consolidation}

Now, suppose that we are in the steady state under myopic fiscal policy where the ratio of debt to GDP equals 103\%. This subsection addresses the question whether it is possible to increase welfare by imposing the SBC and thereby induce debt consolidation and, if so, which is the optimal parameter combination of $\kappa$ and $b^{r e f}$ that the supranational institution should choose.

For three particular combinations of $\kappa$ and $b^{\text {ref }}$ (see below), Figure 4 shows the transition from the steady state without SBC (where $\kappa=0$ ) to a new steady state with SBC (where $\kappa>0$ and $\left.b^{\text {ref }} \geq 0\right)$. In all three cases I set $\kappa>0$ from period $j=1$ onwards. The figure shows the ratio of debt to GDP, the tax rate, and the fine payments (as specified in 34). In all three cases the introduction of the SBC induces a transition to a new steady state. The new steady state and the time to reach the new steady state depend on $\kappa$ and $b^{\text {ref }}$.

Now the question is: Which is the optimal parameter combination of $\kappa$ and $b^{r e f}$ that weighs the costs of higher taxes and fine payments during the period of consolidation to the

\footnotetext{
${ }^{19}$ This is numerically confirmed by setting $\kappa=0.003$ for periods $j=0, \ldots, T$ and $\gamma=0.979$ for periods $j=1, \ldots, T$.
} 
Debt to GDP
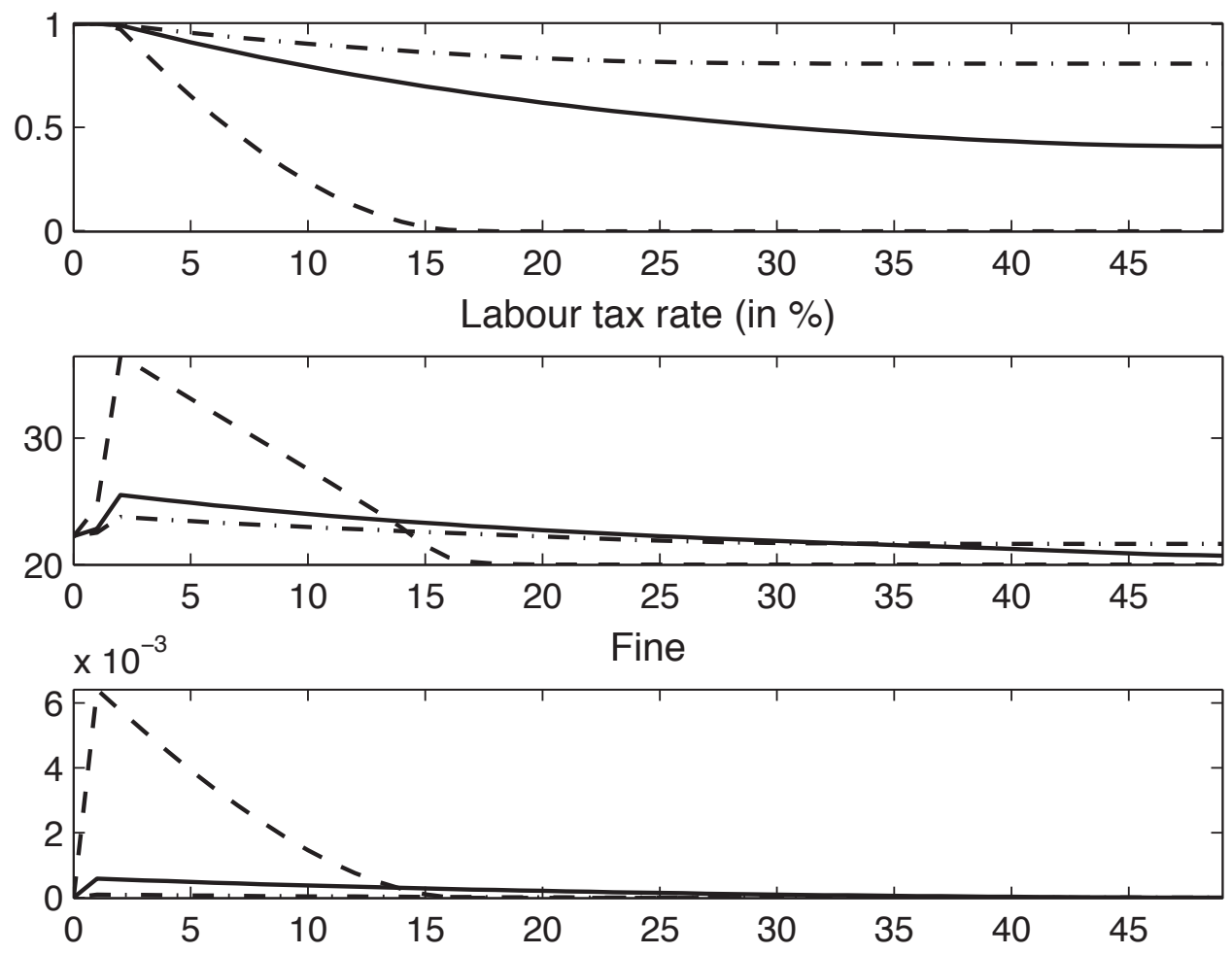

Figure 4: Debt consolidating transition from the steady state without SBC $(\kappa=0)$ to a new steady state with SBC $(\kappa>0)$ for different combinations of $\kappa$ and $b^{r e f}$, respectively: dash-dotted line $(0.001,0.4)$, solid line $(0.002,0.2)$, dashed line $(0.013,0)$.

long term benefits of lower taxes? To answer this question, as before, I measure welfare costs of the inferior policy in terms of consumption of the superior policy. Since the conjecture is that welfare increases by introducing the SBC, welfare costs of remaining in the steady state without SBC and not consolidating are measured relative to a transition to a new steady state with SBC. That is, positive welfare costs imply welfare gains of consolidation. Let welfare in the steady state without SBC be denoted by $W^{M}$ and welfare for some particular path of consolidation be denoted by $W^{s b c}$, where $M$ and $s b c$ denote the respective regimes. $W^{M}$ is defined as the discounted sum of household period utility under perfect foresight conditional on the state of the economy in period $j=0$ being the steady state associated with regime $M$ and remaining there forever:

$$
W^{M}=\sum_{j=0}^{\infty} \beta^{j} u\left(c_{t+j}^{M}, n_{t+j}^{M}\right)
$$

where $c_{t+j}^{M}$ and $n_{t+j}^{M}$ denote consumption and working time under regime $M$. Welfare of a 
transition from regime $M$ to regime $s b c$ is then defined as the discounted sum of household period utility conditional on the state of the economy in period $j=0$ being the steady state associated with regime $M$, changing to regime $s b c$ in periods $j=1, \ldots, T$ and taking into account the period of transition:

$$
W^{s b c}=\sum_{j=0}^{\infty} \beta^{j} u\left(c_{t+j}^{s b c}, n_{t+j}^{s b c}\right),
$$

where $c_{t+j}^{s b c}$ and $n_{t+j}^{s b c}$ denote consumption and working time in case of consolidation. This definition implies that $W^{s b c}$ is a function of $\kappa$ and $b^{r e f}$. Then, for the given calibration, welfare costs of not consolidating are given by

$$
\Lambda^{M s b c}=1-\exp \left[\left(W^{M}-W^{s b c}\right)(1-\beta)\right] .
$$

Figure 5 plots $\Lambda^{M s b c} \times 100$ as a function of $\kappa$ and $b^{r e f}$. The figure shows that for $\kappa \in$ $[0.001,0.013]$ and $b^{\text {ref }} \in[0,0.45]$ there are welfare gains from consolidation, i.e. $\Lambda^{M s b c} \geq 0$. For any parameter combination within this range, the introduction of the SBC and the induced reduction of debt enhance welfare. The maximum welfare gain can be obtained for $\kappa=0.002$ and $b^{r e f}=0.2$. It amounts to $\Lambda^{M s b c}=0.099 \%$. Thus, the supranational institution should set a proportional fine of $0.4 \%$ of GDP per unit of debt exeeding the reference value which in turn should be set to approximately $40 \%$ of GDP. Notice that this in turn implies that it is not optimal to induce a complete reduction of debt to zero.

When looking only at the effects of $\kappa$ in Figure 5, the highest welfare gains can be realized for values in the range of, approximately, 0.0015 to 0.005 . In particular, there are large increases in $\Lambda^{M s b c}$ for low values of $\kappa$, suggesting that already small fine payments reduce the attractiveness of borrowing and induce substantial consolidation efforts. When looking only at the effects of $b^{\text {ref }}$, the highest welfare gains can be realized for values in the range of, approximately, 20 to $50 \%$ of debt to GDP. While higher values of $b^{\text {ref }}$ do not excert enough pressure to consolidate, very low values of $b^{\text {ref }}$, in particular when combined with high fines, imply high distortions in the near future.

Returning to Figure 4, the solid line shows the transition path for the optimal parameter combination. It takes about 50 quarters to reduce debt to the target value of $40 \%$ of GDP. The tax rate increases for about 30 quarters to pay back outstanding debt, before it converges to a lower long run level given the lower permanent interest payments. The fine payments increase to a maximum of approximately $0.1 \%$ of GDP in period $j=1$ and then converge 


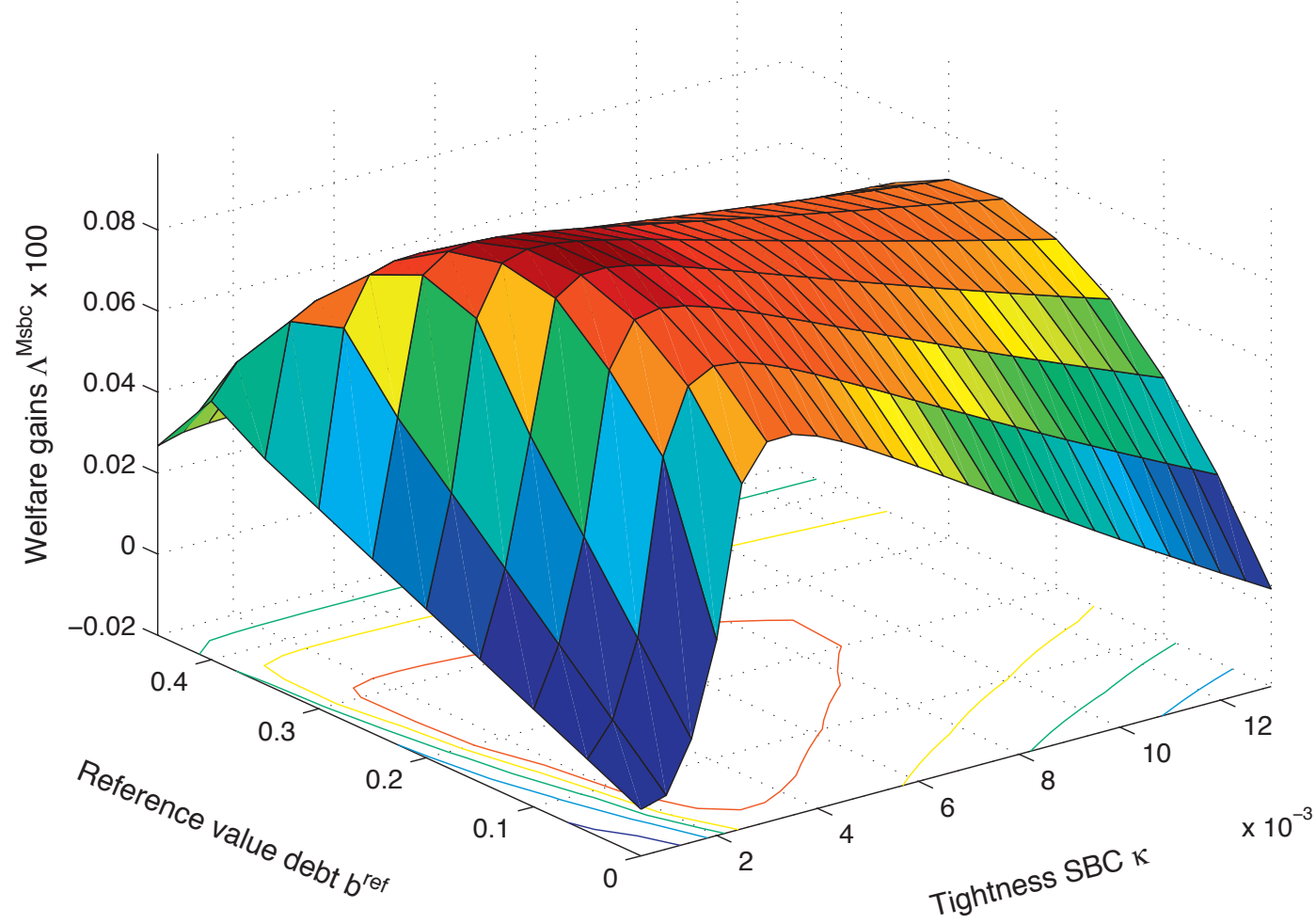

Figure 5: Welfare gains of consolidation $\Lambda^{M s b c} \times 100$ as a function of the reference value of debt $b^{\text {ref }} \in[0,0.45]$ and the tightness of the SBC $\kappa \in[0.0005,0.013]$.

to zero as debt approaches its reference value. Exemplarily, the dash-dotted line in Figure 4 shows the transition path for a relatively loose-in terms of consolidation incentives-parameter combination, i.e. for $\kappa=0.001$ and $b^{r e f} / y=80 \%$, which is associated with welfare gains of $0.052 \%$. Reducing debt from $100 \%$ to $80 \%$ of GDP already leads to substantial welfare gains while only being associated with mildly increasing tax rates and fine payments. The dashed line shows the transition path for a relatively tight parameter combination, i.e. for $\kappa=0.013$ and $b^{r e f} / y=0$, which is associated with welfare gains of $0.004 \%$. Here, the adjustment to the new steady state is completed within only 15 quarters. Induced by high fine payments, debt is reduced to zero through a sharp increase of the tax rate which in turn almost completely outweighs the long term benefits. In sum, however, there is a wide range of parameter combinations where the long run benefits dominate and debt consolidation is welfare enhancing. 


\subsection{Short run dynamics under a soft borrowing constraint}

After showing that by imposing the SBC it is possible to eliminate distortions affecting the non-stochastic steady state of the economy, in this subsection I look at the short run welfare costs of myopic fiscal policy under a SBC, as compared to Ramsey-optimal policy.

Following Schmitt-Grohé and Uribe (2007), both regimes are calibrated to have the same non-stochastic steady state in order to concentrate on welfare costs of a distorted stochastic steady state. In particular, Ramsey-optimal policy is characterized by setting $\gamma=1$ and $\kappa=0$. As before, let this regime be denoted by $R$. Myopic fiscal policy under a SBC, denoted by $S B C$, is characterized by setting $\gamma=0.979, \kappa=0.005$, and $b^{\text {ref }}=0$. These values imply zero debt in the non-stochastic steady state for a government which would otherwise accumulate debt up to $103 \%$ of GDP if the SBC was not imposed (see Section 4.1). The value for $\kappa$ is the lowest possible value for this parameter that still implies the same allocation in the non-stochastic steady state under both regimes up to the fourth significant digit. All other parameters and functional forms are set according to the baseline calibration, in both regimes.

Based on (26), welfare under each regime $i=R, S B C$, conditional on the state of the economy in period $j=0$ being the common non-stochastic steady state under both regimes, is given by

$$
V_{t}^{i} \equiv E_{t} \sum_{j=0}^{\infty} \beta^{j} u\left(c_{t+j}^{i}, n_{t+j}^{i}\right),
$$

where $c_{t+j}^{i}$ and $n_{t+j}^{i}$ denote the particular plans for consumption and working time under regime $i$. Using (36), the corresponding expression to (31) gives welfare costs of regime $S B C$ relative to regime $R$ as

$$
\lambda^{s r}=1-\exp \left[\left(V^{S B C}-V^{R}\right)(1-\beta)\right]
$$

To compute $\lambda^{s r}$, I use the policy functions for $V_{t}^{S B C}$ and $V_{t}^{R}$ approximated up to second order accuracy which I evaluate at the common non-stochastic steady state $x_{0}=\bar{x}$ :

$$
V^{i}\left(x_{0}, 0\right) \approx V^{i}(\bar{x}, 0)+\frac{1}{2} V_{\omega \omega}^{i}(\bar{x}, 0) \omega^{2}
$$

Identical non-stochastic steady states, i.e. $V^{S B C}(\bar{x}, 0)=V^{R}(\bar{x}, 0)$, imply that welfare costs are determined by the second derivatives of the policy functions with respect to uncertainty, $V_{\omega \omega}^{S B C}$ and $V_{\omega \omega}^{R}$, and the parameter scaling the standard deviations of the exogenous shocks 
$\omega:$

$$
\lambda^{s r}=1-\exp \left[\left(V_{\omega \omega}^{S B C}-V_{\omega \omega}^{R}\right) \frac{\omega^{2}}{2}(1-\beta)\right] .
$$

For the standard deviations of the innovations given in the baseline calibration (see Section 3.1 ), short run welfare costs of myopic fiscal policy under a SBC amount to $\lambda^{s r}=0.0010 \%$. This value indicates that welfare costs associated with shifts of the stochastic steady state are quantitatively negligible since $\lambda^{s r}$ is one to two orders of magnitude smaller than the welfare costs computed in the previous subsections (see $\lambda^{M}, \Lambda^{R M}$, and $\left.\Lambda^{M s b c}\right) \cdot{ }^{20}$ To illustrate the robustness of this result to the calibration, I artificially double the standard deviations of the innovations. The implied welfare costs remain small, although they increase to $\lambda^{s r}=0.0040 \%$. These figures show that, for the given calibration, it is welfare-enhancing to implement the SBC since the associated welfare gains of reducing distortions affecting the non-stochastic steady state by far outweigh the welfare costs of increasing the costs of using debt to smooth taxes over the cycle.

To further illustrate this finding, I also consider a balanced budget regime as a particular, well-known alternative to prevent debt accumulation. The balanced budget regime is characterized by letting the tax rate respond endogenously in a model without debt. The government budget constraint is then given by

$$
g_{t}=\tau_{t} w_{t} n_{t}
$$

The calibration and functional forms of this regime are the same as for the other two regimes such that the non-stochastic steady state is the same under all three regimes. Compared to Ramsey-optimal policy, a balanced budget regime is associated with welfare costs of $0.0011 \%$ and $0.0042 \%$ for the baseline calibration and the alternative calibration of the standard deviations, respectively. As before, these numbers illustrate the limited gains of optimal fiscal policy over the cycle as compared to improved long run policies. Moreover, they show that the SBC is slightly preferable in terms of welfare to a balanced budget regime since it allows for the use of debt to smooth taxes, but that quantitatively the two regimes are similar when looking only at short run effects.

To analyze the dynamics under regimes $R$ and $S B C$, Figure 6 plots the impulse responses under both regimes to a government spending shock. It shows debt, the tax rate, the fine (as defined in $(6)$ with $I\left[b_{t} ; b^{r e f}\right] \approx L_{t}$ ), and GDP. Debt and the fine are expressed as absolute

\footnotetext{
${ }^{20}$ Moreover, it indicates the limited gains of optimal fiscal policy over the cycle, as in Schmitt-Grohé and Uribe (2007).
} 
deviations from their steady states (which are zero).
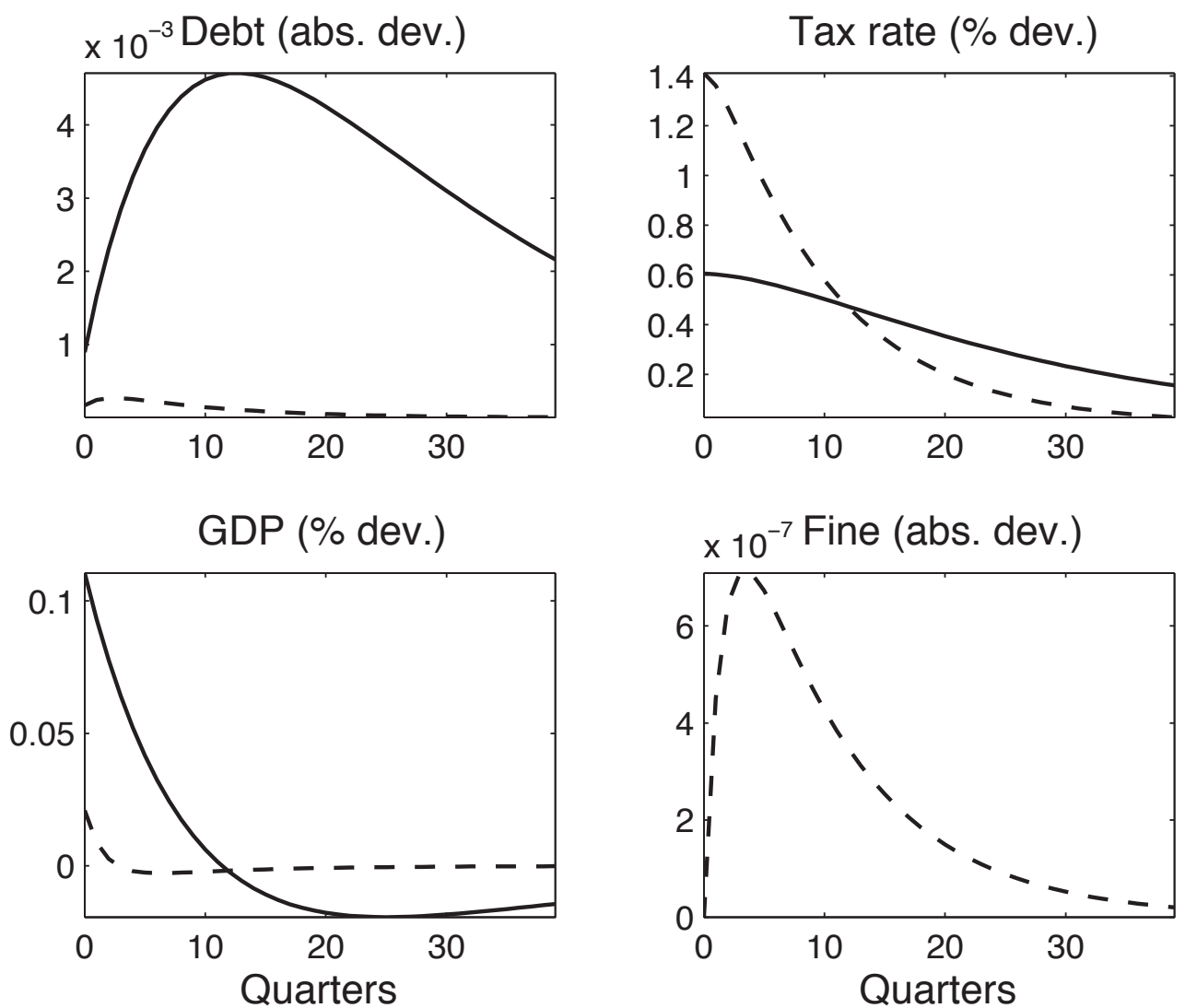

Figure 6: Impulse responses to a government spending shock under Ramsey-optimal policy (solid line) and myopic fiscal policy under a SBC (dashed line).

The solid line shows the impulse responses under Ramsey-optimal policy. We can see how the government uses debt to smooth labour taxes. The dashed line depicts myopic fiscal policy under a SBC. Again, the government uses both its instruments, debt and taxes. However, under a SBC the government largely refrains from using debt to smooth taxes (even though the fine payments are relatively small and only amount to about $7 \times 10^{-7}$ at the maximum). In sum, this subsection shows that short run welfare costs of myopic fiscal policy under a SBC are relatively small as compared to the gains of the SBC from the elimination of distortions affecting the non-stochastic steady state.

\section{Discussion}

Before I analyze the sensitivity of the results to alternative parameterizations, I discuss three alternative assumptions on the structure of the model. 


\subsection{Welfare gains under alternative assumptions}

The proposed SBC is assumed to be paid to a supranational institution to loosely reflect the arrangements of the SGP. This assumption implies that fine payments constitute social costs to the economy, as can be seen from the resource constraint (9). Accordingly, already small values for $\kappa$ imply high costs of using debt and hence strong incentives to reduce excessive borrowing. Alternatively, I assume that the fine payments are private costs, i.e. they are redistributed to the household in a lump-sum way. This assumption reduces the costs of violating the SBC for a given value of $\kappa$. Then, to bring down debt to zero in steady state (from 103\% of GDP for $\gamma=0.979$ ), the tightness of the SBC has to increase to $\kappa \geq 0.02$ as compared to the base model where any $\kappa \geq 0.003$ implies zero debt in steady state. However, there is no natural upper bound for $\kappa$ which can be set, for example, by changing the constitution. Hence, the alternative specification does not alter the general effectiveness of the SBC. Moreover, under the alternative assumption welfare in steady state is affected in the same way for $\kappa \geq 0.02$ because then steady state debt is zero such that there are no fine payments.

In the analysis of Section 4, I set the value of government consumption to $\bar{g}=0.1$ such as to obtain a ratio of $\bar{g} / y=0.2$ under Ramsey-optimal policy. This assumption implies that myopic fiscal policy leads to an increase of the ratio $\bar{g} / y$ because the steady state level of output $y$ is an increasing function of $\gamma$, whereas $\bar{g}$ stays fixed. Thus, welfare costs of myopic fiscal policy include the increase of the share of government consumption (which here is a waste of resources) in GDP. To isolate the welfare costs of positive levels of debt from this composition effect of GDP the ratio $\overline{g / y}$ has to be constant across regimes. Following this alternative assumption, using the measure of welfare costs in (31), and approximating the policy functions up to second order accuracy yields that welfare costs amount to $\lambda^{M^{\prime}}=$ $0.022 \%$ (for $\gamma=0.979$ ). This number is one order of magnitude smaller than the costs as computed in Section 4.1 (where $\lambda^{M}=0.353 \%$ ). However, the introduction of the SBC is as effective as before and more than $99 \%$ of these costs can be eliminated by preventing excessive borrowing. Moreover, this alternative specification implies economically implausible behavior of fiscal policy in the short run since it implies that fiscal policy is set such as to hold the ratio $\overline{g / y}$ constant in response to exogenous shocks.

Next, the model's single endogenous state variable is debt. The main source of welfare costs of myopic fiscal policy stems from a distorted steady state of this variable. The specification of the SBC directly addresses this distortion as it is based on the level of debt. To 
assess the effects of a second endogenous state variable in the model, I analyze myopic fiscal policy and the introduction of the SBC in an economy with capital. Here, the government is restricted to have the same instruments, i.e. it can tax labour income and issue one-period non-state-contingent bonds. I assume the production function to be Cobb-Douglas using labour and capital as inputs and I set the production elasticity of capital to 0.34 , the rate of depreciation to 0.025 , and all other parameters and functional forms follow the baseline calibration. It turns out that welfare costs of myopic fiscal policy are larger in this alternative model. Using (31) and approximating the policy functions for the welfare measures up to second order accuracy, welfare costs for $\gamma=0.979$ amount to $\lambda^{M^{\prime \prime}}=1.43 \%$. These costs are four times larger than the costs in the model without capital. Capital creates an additional channel through which myopic fiscal policy reduces welfare. Higher taxes on labour depress working time and thus the return on capital. This reduces the attractiveness of capital accumulation and hence the stock of capital in the long run. However, imposing the SBC with $\kappa=0.005$ in this model brings down the steady state level of debt to zero, again eliminating more than $99 \%$ of these costs.

Finally, the model considers a closed economy. The alternative assumption of a small open economy, without changing the functioning of the SBC, would complicate the analysis since new assumptions would be needed to remove the unit root from the system which is typically present in these models (see Schmitt-Grohé and Uribe, 2003).

\subsection{Sensitivity analysis}

In this subsection, I first discuss the specification of the SBC before I analyze the sensitivity of the results to alternative parameters in the utility function. The SBC is specified in terms of the absolute level of debt $b_{t}$. Alternatively, I consider a specification of the SBC in terms of the ratio of debt to GDP $b_{t} / y_{t}$. This assumption leaves all the results virtually unchanged. Since there is no growth in the model, the specification in the absolute level of debt just simplifies the analysis.

There are two points to be addressed concerning the second order approximation of the logistic function: One with respect to the long run analysis and one with respect to the short run analysis. For the given calibration and $\kappa=0.005$ (as in Section 4.3) the second order approximation to the policy function for $f_{t}$ is given by:

$$
f_{t}=0.0026 b_{t}+0.3748 b_{t}^{2},
$$


where the constant and the second derivative of the policy function with respect to uncertainty are zero. To reduce excessive borrowing in the long run it is sufficient that the coefficient in (38) multiplying $b_{t}^{2}$ is positive. This ensures that whenever the government would like to issue debt, which is the case for any $\gamma<1$, it has to pay a positive fine. I checked that this coefficient is positive for all reasonable parameter combinations. ${ }^{21}$

Turning to the short run implications, (38) implies that for $b_{t} \in[-0.007 ; 0]$ the fine is negative, turning into a transfer to the economy. This sign reversion would not be the case if the logistic function was used instead and implies that the welfare costs of myopic fiscal policy under a SBC in the short run analysis of Section 4.3 are underestimated. However, since welfare costs of a distorted stochastic steady state amount only to $\lambda^{s r}=0.0010 \%$ and actual fine payments (and hence transfers) are quantitatively negligible for the given calibration (see Figure 6) the approximation of the logistic function does not affect the main results of the analysis. Moreover, by using Dynare ++ , I checked up to a fifth order approximation to the policy functions for the model's endogenous variables that welfare costs are virtually identical to the case of a second order approximation, indicating the limited role of actual fine payments/ transfers for welfare.

Finally, I assess the sensitivity of the results to different values of $\sigma$ and $\varphi$ in the utility function (see 25). In all cases, the value of $\nu$ is chosen such as to obtain a value of working time of $n=0.5$ in the non-stochastic steady state under Ramsey-optimal policy. Welfare costs are measured using the corresponding expressions to (31) and (33) for the case of general CRRA preferences, which are given by

$$
\lambda^{g e n}=1-\left(\frac{V^{M}-V N^{R}}{V^{R}-V N^{R}}\right)^{\frac{1}{1-\sigma}} \text { and } \Lambda^{g e n}=1-\left(\frac{W^{R M}-W N^{R}}{W^{R}-W N^{R}}\right)^{\frac{1}{1-\sigma}}
$$

respectively, and where

$$
V N^{R}=-E_{t} \sum_{j=0}^{\infty} \beta^{j}\left(\frac{\nu\left(n_{t+j}^{R}\right)^{1+\varphi}}{1+\varphi}+\frac{1}{1-\sigma}\right), W N^{R}=-\sum_{j=0}^{\infty} \beta^{j}\left(\frac{\nu\left(n_{t+j}^{R}\right)^{1+\varphi}}{1+\varphi}+\frac{1}{1-\sigma}\right)
$$

and $n_{t+j}^{R}$ denotes working time under Ramsey-optimal policy. The parameters and the results where $\lambda^{g e n}$ is approximated up to second order accuracy are summarized in Table 2. We can see that for both measures welfare costs decrease as $\sigma$ and $\varphi$ increase. However, in all cases

\footnotetext{
${ }^{21}$ Notice that in the deterministic transition scenarios in Section 4.2 there is no need for an approximation of the logistic function since the absence of uncertainty allows using a Newton method to solve simultaneously all the original equations for all periods instead of using perturbation methods.
} 
the introduction of the SBC brings down debt to zero in the non-stochastic steady state and thus eliminates the main source of welfare costs.

Table 2: Welfare costs for different parameters in the utility function.

\begin{tabular}{llllll}
\hline \hline \multicolumn{3}{c}{ Parameters } & \multicolumn{2}{c}{ Welfare costs ${ }^{a}$} \\
\hline$n^{R}$ & $\nu$ & $\sigma$ & $\varphi$ & $\lambda^{g e n} \times 100$ & $\Lambda^{\text {gen }} \times 100$ \\
\hline 0.5 & 1.78 & 0.5 & 0.5 & 0.806 & 0.314 \\
0.5 & 4 & 1 & 1 & 0.353 & 0.141 \\
0.5 & 20 & 2 & 2 & 0.166 & 0.067 \\
0.5 & 100 & 3 & 3 & 0.108 & 0.044 \\
\hline \hline
\end{tabular}

\section{Conclusions}

The standard Ramsey approach to optimal taxation cannot account for the high and persistent levels of government debt that we observe in many OECD countries. Assuming a myopic policy maker implies empirically more realistic positive levels of debt. In the absence of lump-sum taxation the associated allocation is inferior in terms of welfare to the allocation under Ramsey-optimal policy and implies welfare costs of up to $0.35 \%$ of the Ramsey consumption stream.

The paper proposes a legal restriction in the form of a soft borrowing constraint on sovereign debt which is modeled as a proportional fine on excessive debt and resembles features of the SGP. The constraint prevents excessive borrowing in the long run and thereby eliminates most of the welfare costs of myopic fiscal policy. The short run welfare costs of the soft borrowing constraint, resulting from higher costs of using debt to smooth taxes over the business cycle, are quantitatively negligible. Thus, the paper supports the views of those who like to strengthen the rules of the SGP. It also provides an argument for the inclusion of a debt break into the German constitution or for the advocates of balanced budget rules.

Conditioning the proportionality of the fine payments on some state of the economy, for example the level of output, could reduce the short run welfare cost of the SBC even further. On the other hand, in a medium- or large-scale macroeconomic model with nominal and real frictions the short run costs of the SBC might be larger. I leave both issues for future research. 


\section{References}

Aiyagari, S. R., A. Marcet, T. J. Sargent, and J. Seppälä (2002): "Optimal Taxation without State-Contingent Debt," Journal of Political Economy, 110(6), 1220-1254.

Aiyagari, S. R., And E. R. McGrattan (1998): "The optimum quantity of debt," Journal of Monetary Economics, 42(3), 447 - 469.

Alesina, A., And R. Perotti (1994): "The Political Economy of Budget Deficits," NBER Working Papers 4637, National Bureau of Economic Research, Inc.

Alesina, A., And G. Tabellini (1990): "A Positive Theory of Fiscal Deficits and Government Debt," The Review of Economic Studies, 57(3), 403-414.

Barro, R. J. (1979): "On the Determination of the Public Debt," Journal of Political Economy, $87(5), 940-71$.

Bayoumi, T., M. Goldstein, and G. Woglom (1995): "Do Credit Markets Discipline Sovereign Borrowers? Evidence from the U.S. States," Journal of Money, Credit and Banking, 27(4), 1046-59.

Beetsma, R. M., M. P. Ribeiro, and A. Schabert (2008): "A Comparison of Debt and PrimaryDeficit Constraints," CEPR Discussion Paper Series, No.689\%.

Chari, V., And P. J. Kehoe (1999): "Optimal fiscal and monetary policy," in Handbook of Macroeconomics, ed. by J. B. Taylor, and M. Woodford, Handbook of Macroeconomics, chap. 26, pp. 1671-1745. Elsevier.

ECB (2009): "Monthly Bulletin november 2009," Monthly bulletin, European Central Bank.

Elmendorf, D. W., And N. G. Mankiw (1999): "Government Debt," in Handbook of Macroeconomics, ed. by J. B. Taylor, and M. Woodford, Handbook of Macroeconomics, chap. 25, pp. 1615-1669. Elsevier.

Engen, E. M., And R. G. Hubbard (2004): "Federal Government Debt and Interest Rates," NBER Working Papers 10681, National Bureau of Economic Research, Inc.

Franses, P., And D. van DiJK (2000): Nonlinear Time Series Models in Empirical Finance. Cambridge University Press.

Gale, W. G., And P. R. Orszag (2003): "Economic Effects of Sustained Budget Deficits.," National Tax Journal, 56(3), 463 - 485 .

Grossman, H. I., And J. B. VAn Huyck (1988): "Sovereign Debt as a Contingent Claim: Excusable Default, Repudiation, and Reputation.," American Economic Review, 78(5), 1088.

Heaton, J., AND D. J. LuCAS (1996): "Evaluating the effects of incomplete markets on risk sharing..," Journal of Political Economy, 104(3), 443. 
Jonsson, M., And P. Klein (2003): "Tax distortions in Sweden and the United States," European Economic Review, 47(4), $711-729$.

Kumhof, M., And I. Yakadina (2007): "Politically Optimal Fiscal Policy," IMF Working Papers 07/68, International Monetary Fund.

Laubach, T. (2009): "New Evidence on the Interest Rate Effects of Budget Deficits and Debt," Journal of the European Economic Association, 7(4), 858-885.

LucAs, JR., R. E. (2003): "Macroeconomic Priorities.," American Economic Review, 93(1), 1 - 14.

Neumeyer, P. A., And F. Perri (2005): "Business cycles in emerging economies: the role of interest rates," Journal of Monetary Economics, 52(2), 345 - 380.

OECD (2009): "Economic Outlook Nov. 2009," Economic Outlook 86, OECD.

(2009b): "National Accounts at a Glance - 2009 edition," National accounts database, OECD.

Persson, T., And L. E. O. Svensson (1989): "Why a Stubborn Conservative Would Run a Deficit: Policy with Time-Inconsistent Preferences," The Quarterly Journal of Economics, 104(2), 325-45.

Schmitt-Grohé, S., And M. Uribe (1997): "Balanced-budget rules, distortionary taxes and aggregate instability.," Journal of Political Economy, 105(5), 976.

(2003): "Closing small open economy models," Journal of International Economics, 61(1), $163-185$.

(2004): "Solving dynamic general equilibrium models using a second-order approximation to the policy function," Journal of Economic Dynamics and Control, 28(4), 755-775.

(2007): "Optimal simple and implementable monetary and fiscal rules," Journal of Monetary Economics, 54(6), $1702-1725$.

Stockman, D. R. (2001): "Balanced-Budget Rules: Welfare Loss and Optimal Policies," Review of Economic Dynamics, 4(2), 438-459.

\section{A Derivation of the implementability constraint}

This appendix shows in detail how to derive the sequence of implementability constraints. To start with, substitute out prices $R_{t}$ and $\tau_{t}$ in the household's budget constraint (2) by using the household's first order conditions (4) and (5) to obtain

$$
c_{t}+b_{t+1}\left[\beta E_{t} \frac{u_{c, t+1}}{u_{c, t}}-\phi \frac{b_{t+1}}{y_{t}}\right]=\frac{-u_{n, t} n_{t}}{u_{c, t}}+b_{t},
$$

where $\Phi=\pi_{t}$ was used. Rewrite (40) as

$$
b_{t}=c_{t}+\frac{u_{n, t} n_{t}}{u_{c, t}}-\phi \frac{b_{t+1}^{2}}{y_{t}}+\beta E_{t}\left(\frac{u_{c, t+1}}{u_{c, t}}\right) b_{t+1} .
$$


Note that $b_{t}$ in (41) is non-state-contingent and thus the same for all future states of the economy.

For convenience, define $z_{t}=c_{t}+\frac{u_{n, t} n_{t}}{u_{c, t}}-\phi \frac{b_{t+1}^{2}}{y_{t}}$ in (41) which yields

$$
b_{t}=z_{t}+\beta E_{t}\left(\frac{u_{c, t+1}}{u_{c, t}} b_{t+1}\right) \text {. }
$$

Then iterate forward (42), i.e. replace $b_{t+1}$ in (42) by the right hand side of (42), with the time index adjusted one period ahead

$$
\begin{aligned}
b_{t} & =z_{t}+\beta E_{t}\left\{\left(\frac{u_{c, t+1}}{u_{c, t}}\right)\left[z_{t+1}+\beta E_{t+1}\left(\frac{u_{c, t+2}}{u_{c, t+1}}\right) b_{t+2}\right]\right\} \\
& =z_{t}+\beta E_{t}\left\{\left(\frac{u_{c, t+1}}{u_{c, t}}\right) z_{t+1}+\beta\left(\frac{u_{c, t+1}}{u_{c, t}}\right) E_{t+1}\left(\frac{u_{c, t+2} b_{t+2}}{u_{c, t+1}}\right)\right\} \\
& =z_{t}+\beta E_{t}\left\{\left(\frac{u_{c, t+1}}{u_{c, t}}\right) z_{t+1}+\beta \frac{1}{u_{c, t}} E_{t+1}\left(u_{c, t+2} b_{t+2}\right)\right\} \\
& =z_{t}+\beta E_{t}\left(\frac{u_{c, t+1}}{u_{c, t}} z_{t+1}\right)+\beta^{2} E_{t}\left(\frac{u_{c, t+2}}{u_{c, t}} b_{t+2}\right)
\end{aligned}
$$

where the last equality used the law of iterated expectations. Repeating this substitution $j$ times for future bond holdings $b_{t+j}$ yields

$$
b_{t}=z_{t}+\beta E_{t}\left(\frac{u_{c, t+1}}{u_{c, t}} z_{t+1}\right)+\beta^{2} E_{t}\left(\frac{u_{c, t+2}}{u_{c, t}} z_{t+2}\right)+\ldots+\beta^{j+1} E_{t}\left(\frac{u_{c, t+j+1}}{u_{c, t}} b_{t+j+1}\right) .
$$

Let $j \rightarrow \infty$ and multiply by $u_{c, t}$

$$
u_{c, t} b_{t}=E_{t} \sum_{j=0}^{\infty} \beta^{j} u_{c, t+j} z_{t+j}+\lim _{j \rightarrow \infty} \beta^{j+1} E_{t}\left(u_{c, t+j+1} b_{t+j+1}\right)
$$

where, using the transversality condition, the last term on the RHS of (44) equals zero:

$$
\lim _{j \rightarrow \infty} \beta^{j+1} E_{t}\left(u_{c, t+j+1} b_{t+j+1}\right)=0 .
$$

Finally, replace $z_{t+j}$ to obtain the sequence of implementability constraints (12) for the incomplete market case

$$
u_{c, t} b_{t}=E_{t} \sum_{j=0}^{\infty} \beta^{j} u_{c, t+j}\left[c_{t+j}+\frac{u_{n, t+j} n_{t+j}}{u_{c, t+j}}-\phi \frac{b_{t+1+j}^{2}}{y_{t+j}}\right] .
$$

\section{B Derivation of the infinite double sum}

This appendix shows how the infinite double sum in (16) which is repeated here for convenience

$$
E_{0} \sum_{t=0}^{\infty}(\gamma \beta)^{t} \alpha_{t} E_{t} \sum_{j=0}^{\infty} \beta^{j} s_{t+j},
$$

can be rewritten as

$$
E_{0} \sum_{t=0}^{\infty}(\gamma \beta)^{t} \mu_{t} s_{t}
$$


where $s_{t+j}=u_{c, t+j}\left(c_{t+j}+\frac{u_{n, t+j} n_{t+j}}{u_{c, t+j}}-\phi \frac{b_{t+j+1}^{2}}{y_{t+j}}\right)$, as above. To start, write out the sums on the LHS

$$
\begin{aligned}
L H S= & E_{0}\left\{\alpha_{0} E_{0} \sum_{j=0}^{\infty} \beta^{j} s_{0+j}\right\}+E_{0}\left\{\gamma \beta \alpha_{1} E_{1} \sum_{j=0}^{\infty} \beta^{j} s_{1+j}\right\}+ \\
& +E_{0}\left\{\gamma^{2} \beta^{2} \alpha_{2} E_{2} \sum_{j=0}^{\infty} \beta^{j} s_{2+j}\right\}+\ldots \\
= & E_{0}\left\{\alpha_{0} E_{0}\left[s_{0}+\beta s_{1}+\beta^{2} s_{2}+\beta^{3} s_{3}+\ldots\right]\right\} \\
& +E_{0}\left\{\gamma \beta \alpha_{1} E_{1}\left[s_{1}+\beta s_{2}+\beta^{2} s_{3}+\beta^{3} s_{4}+\ldots\right]\right\} \\
& +E_{0}\left\{\gamma^{2} \beta^{2} \alpha_{2} E_{2}\left[s_{2}+\beta s_{3}+\beta^{2} s_{4}+\beta^{3} s_{5}+\ldots\right]\right\}+\ldots \\
= & E_{0}\left\{\alpha_{0} s_{0}+\beta \alpha_{0} s_{1}+\beta^{2} \alpha_{0} s_{2}+\beta^{3} \alpha_{0} s_{3}+\ldots\right. \\
& +\gamma \beta \alpha_{1} s_{1}+\gamma \beta^{2} \alpha_{1} s_{2}+\gamma \beta^{3} \alpha_{1} s_{3}+\gamma \beta^{4} \alpha_{1} s_{4}+\ldots \\
& \left.+\gamma^{2} \beta^{2} \alpha_{2} s_{2}+\gamma^{2} \beta^{3} \alpha_{2} s_{3}+\gamma^{2} \beta^{4} \alpha_{2} s_{4}+\gamma^{2} \beta^{5} \alpha_{2} s_{5}+\ldots\right\}
\end{aligned}
$$

where the last equality used the law of iterated expectations. Then factor out the corresponding terms of $s_{t}$

$$
\begin{aligned}
L H S & =E_{0}\left\{\alpha_{0} s_{0}+\left(\beta \alpha_{0}+\gamma \beta \alpha_{1}\right) s_{1}+\left(\beta^{2} \alpha_{0}+\gamma \beta^{2} \alpha_{1}+\gamma^{2} \beta^{2} \alpha_{2}\right) s_{2}+\ldots\right\} \\
& =E_{0}\left\{\alpha_{0} s_{0}+\beta\left(\alpha_{0}+\gamma \alpha_{1}\right) s_{1}+\beta^{2}\left(\alpha_{0}+\gamma \alpha_{1}+\gamma^{2} \alpha_{2}\right) s_{2}+\ldots\right\} \\
& =E_{0}\left\{\left[\alpha_{0}\right] s_{0}+\gamma \beta\left[\frac{\alpha_{0}}{\gamma}+\alpha_{1}\right] s_{1}+\gamma^{2} \beta^{2}\left[\frac{\alpha_{0}}{\gamma^{2}}+\frac{\alpha_{1}}{\gamma}+\alpha_{2}\right] s_{2}+\ldots\right\} .
\end{aligned}
$$

Now, express the square brackets recursively through the sequence of $\mu_{t}=\frac{\mu_{t-1}}{\gamma}+\alpha_{t}$, with $\mu_{-1}=0$

$$
\begin{aligned}
& \mu_{0}=\frac{\mu_{-1}}{\gamma}+\alpha_{0}=\alpha_{0} \\
& \mu_{1}=\frac{\mu_{0}}{\gamma}+\alpha_{1}=\frac{\alpha_{0}}{\gamma}+\alpha_{1} \\
& \mu_{2}=\frac{\mu_{1}}{\gamma}+\alpha_{2}=\frac{\alpha_{0}}{\gamma^{2}}+\frac{\alpha_{1}}{\gamma}+\alpha_{2}
\end{aligned}
$$

The LHS can then be written as

$$
\begin{aligned}
L H S & =E_{0}\left\{\mu_{0} s_{0}+\gamma \beta \mu_{1} s_{1}+\gamma^{2} \beta^{2} \mu_{2} s_{2}+\gamma^{3} \beta^{3} \mu_{3} s_{3}+\ldots\right\} \\
& =E_{0} \sum_{t=0}^{\infty}(\gamma \beta)^{t} \mu_{t} s_{t} \\
& =R H S .
\end{aligned}
$$


